\title{
Low-temperature excitonic, electron-hole and interstitial-vacancy processes in LiF single crystals
}

\author{
S Nakonechnyi ${ }^{1,2}$, T Kärner ${ }^{1}$, A Lushchik ${ }^{1,2}$, Ch Lushchik $^{1}$, V Babin $^{1}$, E Feldbach ${ }^{1}$, \\ I Kudryavtseva ${ }^{1}, \mathrm{P}_{\text {Liblik}}{ }^{1}, \mathrm{~L} \mathrm{Pung}^{2}$ and E Vasil'chenko ${ }^{1}$ \\ ${ }^{1}$ Institute of Physics, University of Tartu, Riia 142, 51014 Tartu, Estonia \\ ${ }^{2}$ Department of Physics, University of Tartu, Tähe 4, 51010 Tartu, Estonia
}

\begin{abstract}
The emission spectra and the excitation spectra of various emissions have been measured in LiF crystals at $9 \mathrm{~K}$ using VUV radiation of $10-33 \mathrm{eV}$. Contrary to the luminescence of selftrapped excitons $(3.4 \mathrm{eV})$, the efficiency of several extrinsic emissions $(4.2,4.6$ and $5.8 \mathrm{eV})$ is very low in the region of an exciton absorption (12.4-14.2 eV). A single exciting photon of $28-33 \mathrm{eV}$ is able to create a primary electron-hole (e-h) pair and a secondary exciton. The tunnel phosphorescence has been detected after the irradiation of LiF by an electron beam or X-rays at $6 \mathrm{~K}$, and several peaks of thermally stimulated luminescence (TSL) at 12-170 K appeared at the heating of the sample. It was confirmed that the TSL at $130-150 \mathrm{~K}$ is related to the diffusion of self-trapped holes ( $\mathrm{V}_{\mathrm{K}}$ centres). The TSL peak at $\sim 160 \mathrm{~K}$ is ascribed to the thermal ionisation of $\mathrm{F}^{\prime}$ centres. The TSL at $20-30 \mathrm{~K}$ and $50-65 \mathrm{~K}$ is caused by the diffusion of interstitial fluorine ions (I centres) or $\mathrm{H}$ interstitials, respectively. The TSL peak at $\sim 13 \mathrm{~K}$, the most intense after electron or X-irradiation, cannot be detected after LiF irradiation by VUV radiation, selectively forming excitons or e-h pairs. The creation of a spatially correlated anion exciton and an e-h pair is needed for the appearance of this peak: an exciton decays into an F-H pair, a hole forms a $V_{K}$ and an electron transforms $H$ into $I$ (an F-I- $V_{K}$ group is formed) or an $\mathrm{F}$ centre into a two-electron $\mathrm{F}^{\prime}$ centre (an $\mathrm{F}^{\prime}-\mathrm{H}-\mathrm{V}_{\mathrm{K}}$ group). The analysis of the elementary components of the 9-16 K TSL showed that a phonon-induced radiative tunnel recombination of $\mathrm{F}^{\prime}-\mathrm{V}_{\mathrm{K}}(5.6 \mathrm{eV}), \mathrm{F}-\mathrm{H}(\sim 3 \mathrm{eV})$ and $\mathrm{F}-\mathrm{V}_{\mathrm{K}}(3.4 \mathrm{eV})$ occurs within these groups.
\end{abstract}

Short Title: Low-temperature excitonic, electron-hole and interstitial-vacancy processes in $\mathrm{LiF}$

Classification numbers: $61.72-\mathrm{Ji} ; 76.30 . \mathrm{Mi} ; 78.55-\mathrm{Fv} ; 78.60-\mathrm{Kn}$

Corresponding author A.Lushchik, e-mail: luch@fi.tartu.ee, fax: +372-7-383033, tel.:+372-7383026 


\section{Introduction}

Face-centred LiF crystals built up of ions with a simple electron structure $\left(1 \mathrm{~s}^{2}\right.$ of $\mathrm{Li}^{+}$and $1 s^{2} 2 s^{2} 2 p^{6}$ of $F^{-}$) have been thoroughly studied by theorists (see, e.g., [1,2]). For a long time, LiF crystals have been used as optical materials with an extremely high transparency region (at $300 \mathrm{~K}$ up to $12 \mathrm{eV} \mathrm{[3]),} \mathrm{as} \mathrm{tissue-equivalent} \mathrm{dosimetric} \mathrm{materials} \mathrm{[4,5]} \mathrm{etc.} \mathrm{In} \mathrm{LiF,} \mathrm{at} \mathrm{8-80}$ $\mathrm{K}$, the creation energy of transverse and longitudinal anion excitons equals 13 and $13.8 \mathrm{eV}$, respectively, the value of the energy gap is $E_{\mathrm{g}} \cong 14.5 \mathrm{eV}$ [3] and the creation energy of cation excitons is $62 \mathrm{eV}$ [6]. So, the intrinsic electronic excitations (EEs) of $\mathrm{LiF}$ are located in a vacuum ultraviolet (VUV) spectral region and for a long time their study has been limited by room or higher temperatures because of the absence of optical windows, which are transparent above $12 \mathrm{eV}$ and are needed as the joint of an excitation source with a lowtemperature cryostat. Only the usage of specially equipped beamlines at synchrotron radiation facilities (e.g., SUPERLUMI station at HASYLAB, Hamburg [7]) allowed to extend the range of spectroscopic low-temperature investigations of EEs in LiF towards the VUV region.

The main aim of the present study is to obtain new data on low-temperature (5-200 K) physical processes at the irradiation of $\mathrm{LiF}$ single crystals by X-rays $(\sim 50 \mathrm{keV})$, electrons $(1.5-30 \mathrm{keV})$ and photons of 6-40 eV. Of particular interest is the experimental separation of elementary stages of the low-temperature processes connected with the selective formation of excitons or electron-hole (e-h) pairs or under conditions of multiplication of EEs, when the absorption of an exciting photon causes the creation of both an e-h pair and a secondary anion exciton. A similar separation of excitonic and e-h processes was previously performed in alkali halides with smaller values of $E_{\mathrm{g}}$ (see [8-10] and references therein).

The investigation of excitonic and e-h processes under photoexcitation at low temperatures in LiF is only at its initial stage. However, a detailed study of LiF crystals Xirradiated at $15 \mathrm{~K}$ by means of the EPR method was carried out long ago. Känzig was the first to detect the EPR signal of self-trapped holes ( $\mathrm{V}_{\mathrm{K}}$ centres) in $\mathrm{LiF}$ [11]. It was shown that a self-trapped hole is defined as a $\mathrm{F}_{2}^{-}$molecule located at two anion sites in a regular region of a crystal lattice. Similar to other face-centred alkali halides, a $V_{K}$ centre in $\mathrm{LiF}$ is oriented along $<110>$ [12]. The so-called $\mathrm{H}$ centre, which is $\mathrm{Br}_{2}^{-}$or $\mathrm{Cl}_{2}^{-}$molecule oriented along $<110>$, located at an anion site and strongly interacting with two neighbouring halogen ions from an anion row, has been revealed by the EPR method in $\mathrm{KBr}$ and $\mathrm{KCl}$ crystals $\mathrm{X}$-irradiated at 10 $\mathrm{K}$ [13]. In $\mathrm{NaCl}$ and $\mathrm{NaF}$ crystals with more close-packed lattice, an $\mathrm{H}$ centre - an anion interstitial neutral with respect to a regular lattice - is oriented along $<111>[8,14]$. $\mathrm{H}$ centres 
have been also detected in LiF crystals irradiated at low temperatures. According to EPR and ENDOR data, the annealing of $\mathrm{H}$ centres oriented along $<111>$ takes place at about $60 \mathrm{~K}$ in the most pure LiF crystals [15]. At the same time, the $\mathrm{H}_{\mathrm{A}}\left(\mathrm{Na}^{+}\right)$centres (an $\mathrm{H}$ centre localized near a $\mathrm{Na}^{+}$impurity ion) with the orientation along $<110>$ have been also detected in $\mathrm{LiF}$ [16]. So far, there is no reliable data on the optical characteristics of the so-called $\alpha$ centre (it exhibits the absorption of halogen ions surrounding an anion vacancy) and I centre (a fluorine ion located at an interstitial site). The point is that the corresponding spectral region of 9-11.8 $\mathrm{eV}$ adjacent to a fundamental absorption of LiF is usually "contaminated" by optically active impurities such as $\mathrm{Na}^{+}, \mathrm{Cl}^{-}, \mathrm{Mg}^{2+}, \mathrm{O}^{2-}$ etc.

On this basis, in addition to standard methods of VUV spectroscopy connected with a detailed study of the reflection spectra of single crystals, we have widely used the highly sensitive luminescent methods, that allowed us to separate intrinsic, impurity and nearimpurity emissions, as well as the methods of low-temperature thermoactivation spectroscopy based on the detection of thermally stimulated luminescence (TSL) and the thermal annealing of radiation-induced optical absorption or EPR signal connected with the presence of holes in the irradiated LiF crystals. Particular emphasis has been put to the origin of an anomalously intense TSL peak at $12-13 \mathrm{~K}$.

\section{Experimental}

The main samples were three groups of nominally-pure LiF single crystals. The LiF-1 crystals were grown by the Stockbarger method after a purification cycle involving manyfold zonemelting. Such purification procedure allowed to remove $\mathrm{Na}^{+}, \mathrm{Cl}^{-}, \mathrm{O}^{2-}$ and $\mathrm{OH}^{-}$impurities, while it was useless against $\mathrm{Mg}^{2+}$ ions. The LiF-2 samples were grown by the Kyropoulos method in an inert atmosphere from the salt undergone chemical purification. These samples contain $\mathrm{Na}^{+}$, and a reduced amount of $\mathrm{Mg}^{2+}$ impurity ions. The LiF-3 crystals were grown by the Stockbarger method from the salt containing $\mathrm{Mg}^{2+}$ and $\mathrm{Ti}^{3+}$. It was possible to measure the transmission of the LiF-1 or LiF-2 samples (with a thickness of $0.8 \mathrm{~mm}$ ) at $295 \mathrm{~K}$ in a spectral region up to 12 and $11.7 \mathrm{eV}$, respectively. A LiF:Na crystal (> $100 \mathrm{ppm}$ of $\mathrm{Na}^{+}$) and a LiF:Mg,Ti standard dosimetric material (TLD-100, $100 \mathrm{ppm}$ of $\mathrm{Mg}^{2+}$ and $10 \mathrm{ppm}$ of $\mathrm{Ti}^{3+}$ ) $[4,5]$ subsequently reported to as LiF-D were used in our experiments as well. Hightemperature TSL (300-700 K) was measured for all types of the samples, previously irradiated at $295 \mathrm{~K}$, at a constant heating rate of $\beta=2.86 \mathrm{~K} \mathrm{~s}^{-1}$ in an atmosphere of flowing nitrogen, using a System 310 TLD Reader. The most intense TSL was observed in LiF-3 and LiF:D samples where the impurity centres are mainly responsible for high-temperature TSL. 
The experiments with synchrotron radiation were mainly performed at the SUPERLUMI station of HASYLAB at DESY, Hamburg (see [7] for details). The excitation spectra of various emissions (selected by a monochromator) were normalized to equal quantum intensities of synchrotron radiation falling onto a crystal. The reference signal for normalization was recorded from a sodium salicylate. The excitation spectra were measured for time-integrated luminescence as well as for the emission detected within one-three time windows (length $\Delta t=0.3-198 \mathrm{~ns}$ ) correlated with the excitation pulses (delayed by $\delta t$ ).

Cathodoluminescence spectra were measured in a wide spectral region of $1.5-12 \mathrm{eV}$ at 6$300 \mathrm{~K}$ at the excitation by an electron gun $(1-30 \mathrm{keV}, 10-100 \mathrm{nA})$. The size of an electron beam spot was about $\sim 0.5 \mathrm{~mm}^{2}$ and the typical thickness of a sample was about $0.5 \mathrm{~mm}$. The cathodoluminescence was simultaneously detected by a two-channel system: in the shortwavelength region of 4-12 eV - a double vacuum grating monochromator employing a double Johnson-Onaka system (dispersion $0.167 \mathrm{~nm} / \mathrm{mm}$ ) and a photomultiplier R6838; in the region of 1.5-6.0 eV - a double prism monochromator and a Hamamatsu H6240 photon counting head. After the electron irradiation of a sample had been stopped, it was possible to register the TSL (for different emissions selected through a double prism monochromator) at the heating of the irradiated sample. Novel results on low-temperature TSL (5-300 K) were also obtained for the LiF crystals preliminary irradiated by X-rays (W, $50 \mathrm{kV}, 20 \mathrm{~mA}$ ) or synchrotron radiation of 13-17 eV (HIGITY station of HASYLAB). TSL (integral or for a certain emission) was measured at the heating of the irradiated sample with a constant rate of $\beta=5 \mathrm{~K} \mathrm{~min}^{-1}$ (X-irradiation, synchrotron radiation) or $\beta=10 \mathrm{~K} \mathrm{~min}^{-1}$ (irradiation by electrons). By going up to a higher value of $\beta$, the maximum of TSL peak undergoes a shift by $3-4 \mathrm{~K}$ in the temperature region of $\sim 40 \mathrm{~K}$ and by $7-8 \mathrm{~K}$ in the region of $150 \mathrm{~K}$.

The EPR spectra were measured with an X-band (9.93 GHz) ESR 231 spectrometer. A continuous-flow helium cryostat (Oxford Instruments, ESR900) was used to keep the samples at the necessary temperature. The thermal annealing of paramagnetic centres was measured in the regime of pulse heating (see Section 4.1 for details).

\section{Intrinsic and extrinsic luminescence in $\mathrm{LiF}$}

Similar to other alkali halides, the fast localization of the free mobile anion excitons, directly created at the photoexcitation of a pure LiF crystal, with the formation of self-trapped excitons (STEs) in a regular region of a lattice is caused by the self-trapping of a hole exciton component resulting in the formation of an $\mathrm{X}_{2}^{-}$dihalide molecule located at two anion sites (see $[8,10,17]$ and references therein). Three main channels of STE decay lead to (i) the 
emission of a typical luminescence, (ii) the formation of a phonon package, i.e. heat release and (iii) the formation of a pair of Frenkel defects (usually an F-H pair) [8-10]. All the three channels of STE decay at $5 \mathrm{~K}$ are thoroughly studied for $\mathrm{KBr}, \mathrm{RbBr}, \mathrm{RbCl}, \mathrm{NaCl}, \mathrm{KI}$ and $\mathrm{RbI}$ crystals, where the efficiencies for the radiative channel and for the channel with defect creation are comparable by the order of magnitude. In some crystals $(\mathrm{NaI}, \mathrm{NaBr})$, the radiative channel of STE decay is dominant at $5 \mathrm{~K}$, while the efficiency of this channel $\eta_{\mathrm{L}}$ does not exceed $1 \%$ in $\mathrm{KCl}$ and $\mathrm{RbCl}$. In $\mathrm{LiF}$ at $5 \mathrm{~K}$, the energy of the direct optical formation of an anion exciton $(\sim 13 \mathrm{eV})$ has been determined from the reflection spectra (see, e.g., $[3,18,19])$ or the absorption spectra of LiF thin films [20]. A detailed analysis of radiative and nonradiative (with defect formation) channels of STE decay in LiF is far from being completed.

Several emission bands were detected in the region of $2-6 \mathrm{eV}$ for a nominally pure $\mathrm{LiF}$ crystal (it is sure now that this crystal contains $\mathrm{Mg}^{2+}, \mathrm{Na}^{+}$and $\mathrm{Cl}^{-}$impurity ions) under $\mathrm{X}$ -

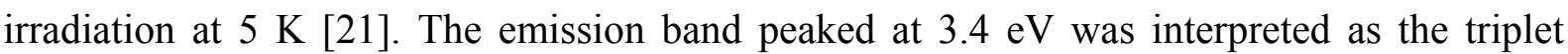
emission of STEs [10,21,22]. The microstructure of triplet excitons (emission at $\sim 3.4 \mathrm{eV}$ ) was thoroughly studied in LiF by ODMR method $[22,23]$. Later the emission bands at 4.6 and 5.8 $\mathrm{eV}$ were ascribed to the radiative decay of intrinsic STE in nominally pure LiF crystals irradiated by single pulses of $350 \mathrm{keV}$-electrons, while the $\sim 3.4 \mathrm{eV}$ emission was considered as the impurity one [24]. In alkali halides, the separation of intrinsic and extrinsic emissions has usually been performed on the basis of low-temperature excitation spectra for various emissions in the purest samples. Unfortunately, the excitation spectra were not measured for the emissions tentatively ascribed in [21-24] to the STE luminescence of LiF.

Figure 1(a) presents the excitation spectra of $3.4 \mathrm{eV}(365 \mathrm{~nm})$ and $4.6 \mathrm{eV}(270 \mathrm{~nm})$ emissions measured in a spectral region of $h v_{\mathrm{exc}}=10-32 \mathrm{eV}$ for a LiF-1 crystal (the purest crystal at our disposal) at $9 \mathrm{~K}$. The $3.4 \mathrm{eV}$ emission efficiency is particularly high at the excitation by photons of $h v_{\mathrm{exc}}=12-14.2 \mathrm{eV}$, i.e. in the region of the reflection peak $(12.95$ $\mathrm{eV})$ connected with the direct optical formation of anion excitons. A deep dip at 12.5-13.5 eV in the excitation spectrum of $3.4 \mathrm{eV}$ emission is partly caused by the higher values of reflection constants $(\sim 60 \%)$ with respect to those at $16-19 \mathrm{eV}$ (less than $5 \%$ ). In addition, the values of $\varepsilon_{2}$ (characterizes absorption) at $12.5-13.2 \mathrm{eV}$ are an order of magnitude as high as those at 16-19 eV [3] and the direct formation of excitons occurs in a thin crystal layer, where mobile excitons can interact with surface or near-surface defects and decay non-radiatively.

Figure 1(b) shows the emission spectra measured at the excitation of LiF-1 by synchrotron radiation of $12.9 \mathrm{eV}$ at $9 \mathrm{~K}$. The spectra were measured for a time-integrated (TI), fast $\left(\mathrm{TW}_{\mathrm{f}}\right)$ and slow luminescence component $\left(\mathrm{TW}_{\mathrm{s}}\right)$. The shape of the emission band with the 
maximum at $3.4 \mathrm{eV}$ and bandwidth of $1 \mathrm{eV}$ is practically the same for a TI signal and for the emission measured within time windows $\mathrm{TW}_{\mathrm{f}}$ and $\mathrm{TW}_{\mathrm{s}}$, the decay time of this emission significantly exceeds $200 \mathrm{~ns}$. Our experimental data confirm that the $3.4 \mathrm{eV}$ emission is originated from the triplet states of intrinsic STEs (see also [10, 21-24]). Besides the $3.4 \mathrm{eV}$ emission band, the emission peaked at $4.6 \mathrm{eV}$ can be detected at the excitation of LiF-1 by $16.2 \mathrm{eV}$ photons, which generate separated electrons and holes (see Fig. 1(b)). The excitation spectrum for the $4.6 \mathrm{eV}$ emission drastically differs from that for the triplet STE emission. The $4.6 \mathrm{eV}$ emission can be efficiently excited by $10.0-12.2 \mathrm{eV}$ photons (i.e. below the edge of fundamental absorption), while the value of $\eta_{\mathrm{L}}$ is significantly lower in the region of exciton absorption ( $\left.h v_{\mathrm{exc}}=12.3-14.5 \mathrm{eV}\right)$. The efficiencies of both emissions are close to each other at $h v_{\mathrm{exc}}=19-25 \mathrm{eV}$, while the values of $\eta_{\mathrm{L}}$ for 3.4 and $4.6 \mathrm{eV}$ emissions drastically differ at $h v_{\mathrm{exc}}=28-32 \mathrm{eV}$. A sharp increase of $3.4 \mathrm{eV}$ emission efficiency in this region is connected with the fact that an exciting photon of $28-32 \mathrm{eV} \mathrm{eV}$ is able to create both a primary e-h pair and a secondary anion exciton, i.e. the process of multiplication of electronic excitations (MEE) gets under way. Such an excitonic MEE mechanism is thoroughly studied for a number of alkali halides (see, e.g., [25]) and the minimum threshold energy of this MEE mechanism in LiF can be estimated as $E_{\mathrm{t}}=E_{\mathrm{g}}+E_{\mathrm{e}}=14.5+13=27.5 \mathrm{eV}\left(E_{\mathrm{e}}\right.$ is the formation energy of an anion exciton). The actual value of $E_{\mathrm{t}}$ slightly exceeds the minimum value, because a part of the energy excess of a primary e-h pair $\left(h v_{\mathrm{exc}}-E_{\mathrm{g}}\right)$ is gained by a photohole, while only a hot conduction electron is able to create a secondary exciton. The width of a valence band in $\mathrm{LiF}$ is about 4-5 eV (see [2] and references therein). So, the MEE process connected with the creation of secondary anion excitons with a typical $3.4 \mathrm{eV}$ emission takes place in $\mathrm{LiF}$ in the whole region of $h v_{\mathrm{exc}}=28-32 \mathrm{eV}$ (see Fig. 1b).

On the other hand, the changes of $\eta_{\mathrm{L}}$ for $4.6 \mathrm{eV}$ emission at $h v_{\mathrm{exc}}=28-32 \mathrm{eV}$ are small, especially if we take into account the small values of reflection constants [3] and practically constant values of the absorption constants [20] in this spectral region. There are no manifestations of MEE processes at $h v_{\mathrm{exc}} \geq 28 \mathrm{eV}$ for the $4.6 \mathrm{eV}$ luminescence. The $4.6 \mathrm{eV}$ emission can be excited in the region of fundamental absorption by photons which generate e-h pairs, while excitons practically do not cause the excitation of this emission. According to our analysis, the $4.6 \mathrm{eV}$ emission is an extrinsic one and can be tentatively related to the electron-hole recombination near impurity-defect associations. A similar situation takes place in a LiF:U crystal, where the efficiency of the impurity emission (uranium complexes) at $11 \mathrm{~K}$ does not rise with the increase of $h v_{\text {exc }}$ from 28 to $40 \mathrm{eV}$ [26]. 
Particular attention has been paid to the cathodoluminescence spectra measured in a wide spectral region of $2-11 \mathrm{eV}$ at $5 \mathrm{~K}$ for different types of $\mathrm{LiF}$ single crystals at our disposal. Contrary to some alkali iodides [8,17] and bromides [27], we failed to detect the emission of free excitons in a spectral region up to $12 \mathrm{eV}$ for $\mathrm{LiF}$ crystals. Cathodoluminescence, analyzed by a double vacuum monochromator, was detected only below $7 \mathrm{eV}$. The emission of STEs was detected in all types of LiF crystals, but the efficiency of this emission is reduced in LiF:D and LiF-3 crystals containing $\mathrm{Mg}^{2+}$ and $\mathrm{Ti}^{3+}$ impurity ions. Figure 2 presents the cathodoluminescence spectra measured for LiF-1 and LiF-3 crystals at $6 \mathrm{~K}$. Besides the STE emission of $3.4 \mathrm{eV}$, weak emission bands at 4-5 and 2-3 eV have been detected in these spectra. The efficiency of the STE emission in LiF-1 is significantly higher than in LiF-3, where the red emission of $\mathrm{Ti}^{3+}$ centres is a dominant one.

The phosphorescence, rapidly damping out with time, was detected in our LiF crystals after the irradiation had been stopped. The phosphorescence exhibits distinctive features of tunnel luminescence (see Section 4.3), which has earlier been studied in highly pure $\mathrm{KCl}$ and $\mathrm{KBr}$ crystals X-irradiated at $4.2 \mathrm{~K}$ (see, e.g., [28,29]). Figure 2 shows the spectra of tunnel luminescence measured 20 min after the irradiation of LiF-1 or LiF-3 by $30 \mathrm{keV}$ electrons at 6 $\mathrm{K}$ had been stopped. The emission with the maximum at $\sim 3.0 \mathrm{eV}$ (bandwidth of $0.95 \mathrm{eV}$ ) and a weak emission at 4-6 eV are detected in these spectra. The subsequent heating of the irradiated sample leads to the appearance of an intense TSL peak at $\sim 13 \mathrm{~K}$. Figure 2 presents also the emission spectra of the TSL at $12-14 \mathrm{~K}$ for the irradiated samples. These spectra will be discussed further in Section 4.3.

The excitation spectra for 3.4, 4.23 and $5.9 \mathrm{eV}$ emissions have been thoroughly measured in LiF samples at $8 \mathrm{~K}$ with the purpose of separating intrinsic and extrinsic emissions. Figure 3 presents fragments of these spectra at $10-15 \mathrm{eV}$. In LiF-1, $3.4 \mathrm{eV}$ emission can be excited by photons of $h v_{\mathrm{exc}}>12 \mathrm{eV}$, but only at $h v_{\mathrm{exc}}>12.4 \mathrm{eV}$ we deal with the behaviour of a pure emission of STEs. Photons of $12.15 \mathrm{eV}$ excite both overlapping broadband emissions with the maxima at 3.4 (bandwidth of $0.9 \mathrm{eV}$ ) and $4.23 \mathrm{eV}$. An extrinsic emission of $4.23 \mathrm{eV}$ is efficiently excited in a narrow region of $h v_{\mathrm{exc}}=12.0-12.4 \mathrm{eV}$ at the edge of fundamental absorption of LiF. The identical narrow excitation band was also detected for $5.9 \mathrm{eV}$ emission, however the values of $\eta_{\mathrm{L}}$ for this emission are relatively high in a wide region of 10.0-12.4 eV. Previously the $\sim 5.9 \mathrm{eV}$ emission was tentatively interpreted as the emission of intrinsic STEs in nominally pure LiF crystals under electron irradiation [24]. Figure 3 also shows the excitation spectrum of $3.4 \mathrm{eV}$ emissions measured at $8 \mathrm{~K}$ for a LiF-2 crystal that contains $\mathrm{Na}^{+}$impurity ions. In this sample, the $3.4 \mathrm{eV}$ emission can be excited also by 11.7- 
$12.0 \mathrm{eV}$ photons, i.e. in a wider spectral region than in LiF-1. According to our direct measurements, the values of absorption constants in the region of fundamental edge at 11.712.0 eV for LiF-2 are significantly higher than for LiF-1 and LiF-3. The presence of a $\mathrm{Na}^{+}$ impurity ion among the neighbouring 6 cations changes the absorption of a fluorine ion, while the emission of such near-impurity localized EEs is close to the triplet emission of STEs.

\section{Thermally stimulated luminescence of $\mathrm{LiF}$ crysatals}

For several decades, the TSL of LiF crystals doped with impurity ions has been used for personal dosimetry of $\mathrm{X}$ - and $\gamma$-rays and thermal neutrons (see, e.g., [4,5,30,31]). In this connection, TSL has been investigated comprehensively for nominally pure and doped LiF crystals previously irradiated at room temperature, while in some cases the samples were previously irradiated at $80 \mathrm{~K}$ ( see [4,5,32-34] and references therein) or 15-20 K [33,35]. Ref. 19 reports our preliminary data on TSL (integral signal) for a LiF-1 crystal X-irradiated (50 $\mathrm{keV}$ ) at $4.2 \mathrm{~K}$. Intense TSL peaks were detected (heating rate of $\beta=2.4 \mathrm{~K} \mathrm{~min}^{-1}$ ) at $10-15$ and $110-150 \mathrm{~K}$, while the intensity of TSL peaks at $20-70 \mathrm{~K}$ is hundreds of times lower. The TSL peaks were tentatively attributed to the recombination of electrons and holes within the groups of spatially correlated defects $(10-15 \mathrm{~K})$ or to the hopping diffusion of interstitial fluorine ions or atoms (I and $\mathrm{H}$ centres, 20-65 K) [19]. Thermal annealing of $\mathrm{V}_{\mathrm{K}}$ centres was studied earlier by means of EPR [11,12,32] and TSL methods [5,32-35].

Following are the novel results on the origin of the TSL peaks at 10-200 K for LiF-1, LiF2, LiF-3 and LiF:D crystals. Figure 4 shows the TSL curves measured for $3.5 \mathrm{eV}$ emission in a wide temperature range of $6-220 \mathrm{~K}$ for LiF-1 and LiF-3 crystals irradiated by an electron beam at $6 \mathrm{~K}$. In order to suppress a tunnel phosphorescence, the heating of the sample was started $25 \mathrm{~min}$ after the irradiation had been stopped. The especially intense TSL is observed in the region of the lowest-temperature peak at $\sim 13 \mathrm{~K}$ and at $120-140 \mathrm{~K}$. TSL peaks at 20-70 $\mathrm{K}$ connected with the hopping motion of I and $\mathrm{H}$ interstitials are also detected.

\subsection{TSL in the region of $100-200 \mathrm{~K}$}

Figures 4 and 5a demonstrate the TSL curves for a LiF-1 crystal preliminary irradiated at 6-8 $\mathrm{K}$. The two intense peaks at 132 and $145 \mathrm{~K}$ and a weak peak at $\sim 165 \mathrm{~K}$ can be separated by measuring the TSL for 3.5 and $4.6 \mathrm{eV}$ emissions. Figure 5a presents also the annealing curves of the EPR signal of $\mathrm{V}_{\mathrm{K}}$ centres for LiF-1 X-irradiated at $77 \mathrm{~K}(50 \mathrm{kV}, 5$ hours). The regime of pulse heating was used for EPR measurements: the crystal was heated up to a certain temperature $T_{1}$ and after an exposure of two minutes rapidly cooled down to $T_{0}$ (the rate of 
relaxation processes is practically zero at $T_{0}$ ). The intensity of the EPR signal was measured at $T_{0}=77 \mathrm{~K}$. Such a heating regime accompanied by measurements after every $10 \mathrm{~K}$ in a region of $80-180 \mathrm{~K}$ is approximately equivalent to the regime of linear heating with $\beta=5 \mathrm{~K} \mathrm{~min}^{-1}$. Figure 5a shows the annealing (under a continuous heating) of the optical absorption band of $\mathrm{V}_{\mathrm{K}}$ centres peaked at $3.6 \mathrm{eV}$ in LiF-1 X-irradiated at $80 \mathrm{~K}$. A sharp decrease of the optical and EPR absorption of $\mathrm{V}_{\mathrm{K}}$ centres occurs at $120-140 \mathrm{~K}$.

An additional illumination of a LiF-1 crystal, X-irradiated at room temperature and cooled down to $80 \mathrm{~K}$, by $4.88 \mathrm{eV}$ photons of a mercury discharge (selected through a monochromator) leads to a subsequent appearance of the TSL peak at $158 \mathrm{~K}$, the intensity of which increases with the rise of the duration of the preliminary illumination. Such photostimulation in the region close to the maximum of the F-absorption band decreases the number of $\mathrm{F}$ centres (measured by the direct optical absorption method) and leads to parallel rise of the $158 \mathrm{~K}$ peak intensity. In our opinion, the TSL peak at $158 \mathrm{~K}$ corresponds to the thermal annealing of the so-called $\mathrm{F}^{\prime}$ centres (two electrons in a field of an anion vacancy). The characteristics of the $\mathrm{F}^{\prime}$ centres have been previously investigated for many alkali halides (including $\mathrm{NaF}$ and $\mathrm{KF}$ ) [36]. However, only a theoretical estimation of the minimum energy for the optical ionization of $\mathrm{F}^{\prime}$ centres $(2.4-2.8 \mathrm{eV})$ has been performed for $\mathrm{LiF}$ [36,37]. According to our data, the intensity of the $158 \mathrm{~K}$ TSL peak can be significantly decreased by the additional stimulation of the irradiated LiF by photons from the theoretically predicted energy region. The shape of the TSL F'-peak can be approximated by first-order kinetics with an activation energy of $E_{\mathrm{a}}=235 \mathrm{meV}$ and a frequency factor of $p_{0}=3.3 \times 10^{5} \mathrm{~s}^{-1}$.

Figure 5a also presents the curves of integral TSL measured for a LiF-1 crystal previously irradiated by synchrotron radiation of 17 or $13.8 \mathrm{eV}$ at $8 \mathrm{~K}$. The photons of these energies create separated electrons and holes or anion excitons, respectively. Selective generation of e$\mathrm{h}$ pairs leads to the appearance of two intense TSL peaks in the region of 120-140 K, i.e. in the region of a sharp decrease of the number of paramagnetic $V_{K}$ centres. On the other hand, photocreation of anion excitons by $13.8 \mathrm{eV}$ photons causes the appearance of an intense 115 $\mathrm{K}$ peak $\left(\mathrm{V}_{\mathrm{K}}\right.$ centres are still stable at this temperature) and a weak TSL at $155 \mathrm{~K}$ connected with a thermal ionization of $\mathrm{F}^{\prime}$ centres. In $\mathrm{X}$-irradiated $\mathrm{LiF}$, the annealing of the EPR signal of H-type centres takes place at 110-120 K [11]. However, it was shown later by the ENDOR method that these $\mathrm{H}$ centres are localized near $\mathrm{Na}^{+}$impurity ions [16]. So, the TSL peak at $115 \mathrm{~K}$ in a LiF-1 crystal irradiated by $13.8 \mathrm{eV}$ photons is connected with the annealing of $\mathrm{H}_{\mathrm{A}}\left(\mathrm{Na}^{+}\right)$centres. Similar to other alkali halides, excitons decay into F-H pairs and a part of $\mathrm{H}$ 
interstitials, highly mobile at $T>55 \mathrm{~K}$, becomes localized near $\mathrm{Na}^{+}$forming $\mathrm{H}_{\mathrm{A}}\left(\mathrm{Na}^{+}\right)$centres (LiF-1 still contains some amount of $\mathrm{Na}^{+}$). The intensity of the $115 \mathrm{~K}$ peak (registered for the $2.9 \mathrm{eV}$ emission) in a $\mathrm{LiF}: \mathrm{Na}(>100 \mathrm{ppm})$ is tens of times as high as that in a LiF-1 crystal irradiated under similar conditions.

Figure $5 b$ presents the thermoactivation characteristics of a LiF-3 crystal that contains $\mathrm{Mg}^{2+}$ and $\mathrm{Ti}^{3+}$ impurity ions. We studied the peculiarities of the annealing of $\mathrm{V}_{\mathrm{K}}$-type centres by means of EPR method. For the EPR study of $\mathrm{V}_{\mathrm{K}}$ centres in LiF-3, it was necessary to increase the duration of X-irradiation by 2-3 times against LiF-1. At low irradiation doses of LiF-3, a preferential localization of both electrons and holes occurs at titanium or magnesium centres and the main accumulation of $\mathrm{V}_{\mathrm{K}}$ (or $\mathrm{V}_{\mathrm{K}}$-type) centres begins after the saturation of the electron-hole processes related to $\mathrm{Mg}^{2+}$ and $\mathrm{Ti}^{3+}$. In LiF-3, the annealing of the EPR signal of the $\mathrm{V}_{\mathrm{K}}$-type centres undergoes three stages: at 130, 145 and 160-180 K. Figure $5 \mathrm{~b}$ also shows a TSL curve measured for a LiF-3 crystal irradiated by $17 \mathrm{eV}$ photons at $8 \mathrm{~K}$. The most intense TSL peak has a maximum at $120 \mathrm{~K}$ and is not accompanied by the decrease of the intensity of EPR signal of the $V_{K}$ centres. The annealing of the EPR signal of "pure" $V_{K}$ centres takes place at $130-140 \mathrm{~K}$ and the $\sim 135 \mathrm{~K}$ TSL peak is registered as well. The TSL peaks at 135, 145 and $\sim 170 \mathrm{~K}$ were detected in LiF-3 irradiated by $30 \mathrm{keV}$ electrons at $6 \mathrm{~K}$ (see Fig. 4). Both e-h pairs and excitons were generated at such an electron irradiation. TSL at $145-185 \mathrm{~K}$ and a weak peak at $\sim 110 \mathrm{~K}$ arise after the illumination of a LiF-3 crystal, $\mathrm{X}-$ irradiated at $295 \mathrm{~K}$ and cooled down to $80 \mathrm{~K}$, by $4.88 \mathrm{eV}$ photons (F-band) (see Fig. 5b).

\subsection{TSL in the region of $20-70 \mathrm{~K}$}

According to the existing experimental data, the interstitial-vacancy processes with the participation of $\mathrm{F}$ centres and interstitial fluorine ions or atoms (I and $\mathrm{H}$ centres, respectively) dominate at $20-65 \mathrm{~K}[15,16,19,33,35]$. We continued the investigation of this TSL region for LiF crystals irradiated by X-rays or an electron beam. TSL was registered for the integrated signal as well as for 3.4, 4.6 and $5.5 \mathrm{eV}$ emissions selected through a monochromator. TSL arises due to several main processes. Firstly, a mobile I centre recombines with an F centre and a released conduction electron subsequently participates in the radiative recombination with a $V_{K}$ centre (STE emission of $3.4 \mathrm{eV}$ ) or a hole localized near an impurity (4.6 eV emission). In addition, a released conduction electron can be captured by an F centre with the formation of an $\mathrm{F}^{\prime}$ centre near a $\mathrm{V}_{\mathrm{K}}$. The $5.5 \mathrm{eV}$ emission arises at the tunnel recombination in an $\mathrm{F}^{\prime}-\mathrm{V}_{\mathrm{K}}$ pair. The TSL peak at $28 \mathrm{~K}$ (see Fig. 4) can be detected for 3.4, 4.6 and $5.5 \mathrm{eV}$ emissions and is caused by the motion of I interstitials. Secondly, TSL can be caused by the 
recombination of a mobile $\mathrm{H}$ centre with an $\mathrm{F}^{\prime}$ centre resulting in the release of an electron and its radiative recombination with a $\mathrm{V}_{\mathrm{K}}$ or impurity/defect centre. A TSL peak at $58 \mathrm{~K}$ (Fig. 4 ) is associated with a hopping diffusion of $\mathrm{H}$ centres.

Figure 6 shows the TSL curves measured for 3.3 and $4.6 \mathrm{eV}$ emissions in LiF-1 Xirradiated at $6 \mathrm{~K}$. Under the used irradiation doses ( 5 and $60 \mathrm{~min}$ ) the intensity of TSL at 20$70 \mathrm{~K}$ is still tens of times lower than at $13 \mathrm{~K}$ or $120-150 \mathrm{~K}$. Peaks at 27, 33, 42, 52 and $60 \mathrm{~K}$ are detected for both emissions, while the relative intensities of the peaks are different. The emission of 2.6-3.8 eV dominates in the TSL peak at $42 \mathrm{~K}$, while $60 \mathrm{~K}$ TSL peak can be easily distinguished for the $4.6 \mathrm{eV}$ emission of an impurity origin. The $2.6-3.8 \mathrm{eV}$ emission includes the STE emission with the maximum at $3.4 \mathrm{eV}$ and the phosphorescence band peaked at $\sim 3 \mathrm{eV}$ and connected with the tunnel recharging of an F-H pair and its transformation into an unstable $\alpha$-I pair. Figure 6 also presents the temperature dependence of the intensity of a steady $3.4 \mathrm{eV}$ emission in LiF-1 under X-ray excitation (excitation is weak and does not change the transmittance of the sample). The quenching of STE emission occurs at $40-55 \mathrm{~K}$ and can be described by the Mott formula with an activation energy of $\sim 65 \mathrm{meV}$.

We made an attempt to detect TSL at 20-70 K after the irradiation of LiF-1 and LiF-3 by synchrotron radiation of $h v_{\mathrm{exc}}=17 \mathrm{eV}$. Such photons create separated electrons and holes. Unfortunately, LiF-1 exhibits a low luminescence efficiency and only a weak I-peak of integrated TSL at $28 \mathrm{~K}$ was reliably detected in this sample (in other temperature regions the signal/noise ratio is smaller than 2). A similar but significantly more intense TSL peak can be detected in electron irradiated or X-irradiated LiF-1 crystals (see Figs. 4 and 6). The peak at $\sim 28 \mathrm{~K}$ is characterized by an activation energy of $E_{\mathrm{a}}=72 \mathrm{meV}$ and corresponds to a hopping motion of I centres. The intensity of cathodoluminescence as well as high-temperature (300$630 \mathrm{~K})$ TSL in LiF-3 is high because of the presence of titanium impurity ions and the efficient radiative recombination of conduction electrons with these impurity centres. As a result, the TSL peaks at 28, 39, 52 and $60 \mathrm{~K}$ can be easily distinguished in LiF-3 after electron irradiation (see Fig. 4). Furthermore, in addition to rather intense peaks at 120-150 K connected with $\mathrm{V}_{\mathrm{K}}$-type centres (see Section 4.1), even weak TSL peaks at 52 and $60 \mathrm{~K}$ have been detected in a LiF-3 crystal after its irradiation by 15 or $17 \mathrm{eV}$ photons. The latter peaks are caused by a radiative recombination of the conduction electrons, released at the interaction of mobile $\mathrm{H}$ centres with $\mathrm{F}^{\prime}$ centres, with hole centres.

\subsection{Origin of TSL in the region of $10-15 \mathrm{~K}$}

The TSL peaks at $10-15 \mathrm{~K}$, the intensity of which is tens of times as high as that for TSL at 
20-80 K, have been revealed in LiF-1, LiF-2 and LiF-3 crystals irradiated by X-rays (20-50 $\mathrm{kV})$ or an electron beam (1.5-30 keV) at 4-6 K. However, the intensity of TSL at 10-15 K measured in LiF:D and LiF:Na crystals for the $3.4 \mathrm{eV}$ emission is significantly lower than in purer LiF crystals. In LiF:D dosimetric material and LiF:Na, the intensity of the $\sim 12 \mathrm{~K}$ TSL peak is approximately the same as for the $58 \mathrm{~K}$ peak related to the diffusion of $\mathrm{H}$ centres. It should be pointed out that the 12-13 K TSL peak was not registered in several works, where the samples were irradiated at $T=15-20 \mathrm{~K}[33,35]$.

The intensity of the tunnel phosphorescence in LiF-1 and LiF-3 crystals decreases by tens of times during the first $10 \mathrm{~min}$ after the irradiation had been stopped and later reaches no more than $0.1 \%$ of the intensity of steady X-ray or cathodoluminescence. Similar to $\mathrm{KCl}$ and $\mathrm{KBr}[28,29]$, the intensity of inertial phosphorescence in LiF at $6 \mathrm{~K}$ drops with time by power law $I \sim t^{-\alpha}$, where $\alpha$ depends on the excitation conditions. This tunnel emission with the maximum at $\sim 3.0 \mathrm{eV}$ and bandwidth of $0.95 \mathrm{eV}$ (see Fig. 2) can be tentatively ascribed to the radiative tunnel recharge of $\mathrm{F}-\mathrm{H}$ pairs. However, the intensity of tunnel phosphorescence decreases by $30 \%$ at the cooling of $\mathrm{LiF}-1$ from 4 to $2.9 \mathrm{~K}$. This suggests a particular freezing of certain lattice vibrations and, probably, a phonon-induced origin of tunnel luminescence.

Figure 7 shows the TSL curves measured at 7-16 K for LiF-1 and LiF-3 crystals irradiated by $30 \mathrm{keV}$ electrons ( 5 to $30 \mathrm{~min}$ ) at $6 \mathrm{~K}$. The TSL measurement was started 10 min after the irradiation had been stopped. The luminescense of $(3.4 \pm 0.1)$ or $(5.4 \pm 0.1) \mathrm{eV}$ was selected by a double prism monochromator. The TSL at 7-16 $\mathrm{K}$ in LiF-1 and LiF-3 have been quantitatively analyzed by decomposing a TSL into the components described by the first order kinetics. The activation energies $E_{\mathrm{a}}$ and frequency factors $p_{0}$ that characterize the TSL elementary peaks measured for 3.4 or $5.4 \mathrm{eV}$ emissions have been determined. In LiF-1, the TSL of $5.4 \mathrm{eV}$ contains a peak with the maximum at $12.7 \mathrm{~K}$ and $E_{\mathrm{a}}=9.5 \mathrm{meV}, p_{0}=5.8 \times 10^{2}$ $\mathrm{s}^{-1}$ (see Fig. 7a), while the $3.4 \mathrm{eV}$ TSL consists of two components: a broad peak with $E_{\mathrm{a}}=11.5 \mathrm{meV}, p_{0}=2 \times 10^{3} \mathrm{~s}^{-1}$ and a narrow one with $E_{\mathrm{a}}=24 \mathrm{meV}, p_{0}=2 \times 10^{8} \mathrm{~s}^{-1}$ (Fig. $\left.7 \mathrm{~b}\right)$. In LiF-3, the TSL measured for $3.4 \mathrm{eV}$ emission also contains two peaks characterized by $E_{\mathrm{a}}=9.4 \mathrm{meV}, p_{0}=6 \times 10^{2} \mathrm{~s}^{-1}$ and $E_{\mathrm{a}}=26 \mathrm{meV}, p_{0}=8 \times 10^{9} \mathrm{~s}^{-1}$ (Fig. $7 \mathrm{c}$ ).

The illumination of the irradiated LiF-1 sample at $6 \mathrm{~K}$ by photons of 2.4-2.8 eV, which cause the ionization of $\mathrm{F}^{\prime}$ centres, leads to the appearance of photostimulated luminescence of $3.5 \mathrm{eV}$, the intensity of which decreases by a factor of 3 during $30 \mathrm{~min}$ illumination. Such an $\mathrm{F}^{\prime}$-illumination decreases also the intensity of the TSL peak at $\sim 13 \mathrm{~K}$ (measured for $3.5 \mathrm{eV}$ emission) in the irradiated LiF-1 crystal, while a relative reduction for a broad component of 
TSL is higher than that for a narrow one (see Fig. 7d). The $\mathrm{F}^{\prime}$-illumination of the irradiated LiF-1 leads also to a significant attenuation of the $13 \mathrm{~K}$ TSL peak measured for $5.4 \mathrm{eV}$ emission. The additional illumination of an X-irradiated LiF-1 crystal at $5 \mathrm{~K}$ by $4.88 \mathrm{eV}$ photons that excite $\mathrm{F}$ centres $\left(\mathrm{F} \rightarrow \mathrm{F}^{*}\right.$ transition) causes the increase of the efficiency of tunnel transitions in $\mathrm{F}^{*}-\mathrm{V}_{\mathrm{K}}$ and $\mathrm{F}^{*}-\mathrm{H}$ pairs and attenuation of the TSL at $10-13 \mathrm{~K}$.

The analysis of our experimental data allows to suggest that the groups of spatially correlated defects $\left(\mathrm{F}^{\prime}-\mathrm{H}-\mathrm{V}_{\mathrm{K}}\right.$ and $\left.\mathrm{F}-\mathrm{I}-\mathrm{V}_{\mathrm{K}}\right)$ play a crucial role in a low-temperature TSL at 11-15 $\mathrm{K}$ in the purest LiF crystals. Both anion excitons and e-h pairs are formed during the irradiation of a sample by X-rays or electrons. Just the decay of STEs efficiently results in the creation of F-H pairs of Frenkel defects, while the electrons provide mainly $\mathrm{F} \rightarrow \mathrm{F}^{\prime}$ or $\mathrm{H} \rightarrow \mathrm{I}$ defect transformation and holes form $\mathrm{V}_{\mathrm{K}}$ centres. Two types of tunnel processes are going on in these groups: (i) the $3.4 \mathrm{eV}$ luminescence arises due to the tunnelling of an electron from an $\mathrm{F}$ centre to a $\mathrm{V}_{\mathrm{K}}$ centre, (ii) the 5.6 and $3.4 \mathrm{eV}$ tunnel luminescence are related to the tunnelling of either of the two electrons from an $F^{\prime}$ to a $V_{K}$.

It is well known that two types of tunnel transitions take place in many crystals: (i) direct radiative transition from the ground state of an electron centre to the ground state of a hole centre and (ii) an electron transition from the ground state to the excited state of a hole centre via the excitonic (quasi-excitonic) state, which subsequently undergoes a radiative decay. As a rule, the probability of direct radiative transitions (i) has only a weak dependence on the temperature. In our opinion, both types of tunnel transitions (i) and (ii)) are realized at the tunnelling within $\mathrm{F}^{\prime}-\mathrm{V}_{\mathrm{K}}$ pairs and each of the tunnel luminescence bands (3.4 and $5.6 \mathrm{eV}$ ) could consist of two components related to the cases of (i) and (ii), respectively.

Intense TSL peaks at 11-15 K can be induced already by low-dose X-irradiation (1-6 min) of LiF-1. Under such irradiation conditions an X-ray quantum (50 keV) or even single electron of 10-1.5 keV creates several groups of spatially correlated EEs, but the groups themselves are spatially separated. The intensity of the $13 \mathrm{~K}$ TSL peak increases linearly with time at the initial stage of irradiation. We tried to detect low-temperature TSL (at 10-20 K) after LiF-1 and LiF-3 irradiation by synchrotron radiation of $17 \mathrm{eV}$ (such a photon creates an e-h pair) or 13-15 eV (an exciting photon forms an anion exciton) at $T \leq 8 \mathrm{~K}$. It has been already mentioned (see Sections 4.1 and 4.2) that the selective VUV-irradiation causes intense TSL peaks at $120-160 \mathrm{~K}$ and rather weak peaks at 28 and $60 \mathrm{~K}$. However, we failed to detect TSL at 10-20 K. So, the multiplication of EEs is responsible for the creation of defect groups, which manifest themselves in TSL at 11-15 $\mathrm{K}$ or in photostimulated luminescence. 


\section{Groups of spatially correlated defects and TSL at 10-15 K in LiF crystals}

Radiation creation of the groups of spatially correlated defects (GSCDs) has been revealed in highly pure $\mathrm{KCl}$ and $\mathrm{KBr}$ crystals $\mathrm{X}$-irradiated at $4.2 \mathrm{~K}$. The conclusions on the formation of $\mathrm{F}-\mathrm{V}_{\mathrm{K}}$-I triplets were based on a careful study of TSL and tunnel luminescence $[28,29]$, of the annealing of the EPR signal of $\mathrm{V}_{\mathrm{K}}$ and $\mathrm{H}$ centres [38,39] or of radiation-induced optical absorption and photostimulated luminescence bands connected with a certain type of Frenkel defects (F, H, $\alpha$ and I centres) [40,41]. The creation of F- $V_{K}-I$ triplets by VUV radiation was investigated in $\mathrm{KBr}$ at $8 \mathrm{~K}$ [42]. It was found that the creation of GSCDs is especially high under conditions of multiplication of EEs, when an exciting photon of $16-18 \mathrm{eV}$ is able to create a primary e-h pair and a secondary anion exciton (the so-called excitonic mechanism of multiplication, see [25] for details).

The irradiation of a LiF-1 crystal by X-rays or an electron beam leads to the appearance of the $13 \mathrm{~K} \mathrm{TSL}$ peak, the intensity of which is tens of times as high as of the TSL peaks at 20-70 K. The relative intensity of the $13 \mathrm{~K}$ peak is also high in LiF-2 and LiF-3 and it decreases significantly (with respect to TSL at 20-70 and 120-160 K) only in LiF:D or LiF:Na crystals. In order to explain the efficient creation of the $13 \mathrm{~K}$ TSL peak it should be taken into account, that both short-lived and long-lived (stable) Frenkel defects are formed at the crystal irradiation at $6 \mathrm{~K}$. Kondo et al. first showed that the irradiation of $\mathrm{KBr}$ by nanosecond electron pulses causes mainly the creation of short-lived $\left(\tau=10^{-9}-10^{-3} \mathrm{~s}\right) \mathrm{F}$ and $\mathrm{H}$ centres, while only a few per cent of these defects remain permanent at $8 \mathrm{~K}$ (long-lived defects, $\tau>$ $10^{3} \mathrm{~s}$ ) [43]. The annihilation probability depends on interdefect distance $r_{\mathrm{FH}}$ in the pairs (see, e.g., [8-10]). The spatial separation between genetic $\mathrm{F}$ and $\mathrm{H}$ centres, formed during the sample irradiation at the recombination of conduction electrons with self-trapped holes, is smaller than in the case of F-H creation due to the decay of STEs. In $\mathrm{KCl}$ and $\mathrm{KBr}$, STEs decay at 4.2-6 $\mathrm{K}$ into $\mathrm{F}-\mathrm{H}$ pairs with $r_{\mathrm{FH}}$ exceeding 4-6 interanion distances [8,41,44]. At the same time, long-lived F-H pairs form no more than $10 \%$ of the total amount of the pairs produced in $\mathrm{KCl}$ by the photons that selectively generate electrons and holes (e-h pairs) [45].

In $\mathrm{KCl}$ and $\mathrm{KBr}$ at $4.2 \mathrm{~K}$, the crowdion motion of interstitials along $<110>$ close-packed anion rows ensures the separation of $\mathrm{H}$ and $\mathrm{F}$ centres (inside an F-H pair) by several interanion distances $\left(r_{\mathrm{FH}}>5 d\right)$. The analysis of the data for $\mathrm{KCl}$ showed that the lifetime of $\mathrm{F}$ $\mathrm{H}$ pairs with $r_{\mathrm{FH}}=(2-3) d$ at $8 \mathrm{~K}$ is $\tau=10^{-10}-10^{-6} \mathrm{~s}[9,10]$, while $\mathrm{F}-\mathrm{H}$ with $r_{\mathrm{FH}} \geq 5 d$ are considered as long-lived ones at a low temperature and such $\mathrm{H}$ centres are stable up to $48 \mathrm{~K}$. An F-H pair with $r_{\mathrm{FH}}=4 d$ can be transformed at $4.2 \mathrm{~K}$ into an $\alpha$-I by the photoexcitation of 
an $\mathrm{F}$ crystal up to $2 \mathrm{p}$ excited state [41]. In $\mathrm{LiF}$ irradiated by $300 \mathrm{keV}$ electrons at $11 \mathrm{~K}$, a transient absorption of short-lived F centres attenuates at several stages with the decay time of $\sim 50 \mathrm{~ns}, 30 \mu \mathrm{s}, 700 \mu \mathrm{s}$ and $8 \mathrm{~ms}$, while the relative number of long-lived $\mathrm{F}$ centres is even lower than in $\mathrm{KCl}$ [24].

After the irradiation by electrons at 6-8 $\mathrm{K}$ had been stopped a subsequent heating of LiF-1 causes the appearance of TSL at 11-15 K measured for 3.4 and $5.6 \mathrm{eV}$ emissions. It was mentioned earlier, that the $13 \mathrm{~K}$ TSL peaks were not detected after the irradiation of LiF-1 or LiF-3 by the photons, which form selectively e-h pairs or excitons. So, in our opinion, the 13 $\mathrm{K}$ peak is connected mainly with the processes in $\mathrm{F}^{\prime}-\mathrm{H}-\mathrm{V}_{\mathrm{K}}$ triplets (5.6 and $3.4 \mathrm{eV}$ emissions) and F-I- $\mathrm{V}_{\mathrm{K}}$ triplets (3.4 eV emission) preliminary formed with the participation of a group of spatially correlated EEs - an anion exciton and an e-h pair. An exciton decays into an F-H pair with a relatively small value of $r_{\mathrm{FH}}($ several $d$ ), a hole undergoes a self-trapping and an electron participates in the partial recharging of $\mathrm{F}$ into $\mathrm{F}^{\prime}$ or $\mathrm{H}$ into I. Similarly to other alkali halides, the holes created at LiF irradiation undergo a rapid self-trapping and form $\mathrm{V}_{\mathrm{K}}$ centres.

Thus the creation of GSCDs $\left(\mathrm{F}^{\prime}-\mathrm{H}-\mathrm{V}_{\mathrm{K}}\right.$ or $\mathrm{F}-\mathrm{I}-\mathrm{V}_{\mathrm{K}}$ triplets) is especially efficient under the irradiation conditions, when the energy of an absorbed exciting photon provides the formation of the group of spatially correlated EEs. There are two such possibilities in LiF. Firstly, an exciting photon of $28-32 \mathrm{eV}$ is able to create both a primary e-h pair and a secondary anion exciton (process of EE multiplication, see Section 3). Secondly, the formation energy of cation excitons $\left(1 \mathrm{~s} \rightarrow 2 \mathrm{p}\right.$ electron transitions in $\left.\mathrm{Li}^{+}\right)$in $\mathrm{LiF}$ equals $E_{\mathrm{ec}}=62 \mathrm{eV}[6,46,47]$. This energy is sufficient for the creation of up to four EEs. In sodium halides, the decay of a cation exciton $\left(E_{\mathrm{ec}}=33 \mathrm{eV}\right)$ leads to the formation of an anion exciton and several e-h pairs (2 in $\mathrm{NaCl}$ ) [48]. In our opinion, the decay of a cation exciton in $\mathrm{LiF}$ causes also the formation of an anion exciton. This suggestion is supported by the fact that the efficiency of the ejection of lithium atoms from a LiF crystal surface under $62 \mathrm{eV}$-photon excitation is the same as in the case of $h v_{\mathrm{exc}}=13 \mathrm{eV}$, when the exciting photons merely form anion excitons [49]. Besides an anion exciton, two or three e-h pairs arise at the decay of a cation exciton in a LiF crystal. So, at least one hole undergoes transformation into a self-trapped state $\left(V_{K}\right.$ centre $)$ nearby $F$ and $\mathrm{H}$ centres (products of an STE decay), while all other holes and highly mobile electrons can move to great distances $(>1 \mathrm{~nm})$ from an F centre. One of these electrons can participate in the recharging of an $\mathrm{H}$ centre into an $\mathrm{I}$ centre or an $\mathrm{F}$ centre into an $\mathrm{F}^{\prime}$. As a result, an $\mathrm{F}-\mathrm{I}-\mathrm{V}_{\mathrm{K}}$ or $\mathrm{F}^{\prime}-\mathrm{H}-\mathrm{V}_{\mathrm{K}}$ triplet is formed. Within these defect triplets, the tunnel radiative transitions in F$\mathrm{V}_{\mathrm{K}}, \mathrm{F}^{\prime}-\mathrm{V}_{\mathrm{K}}$ and $\mathrm{F}-\mathrm{H}$ pairs take place. 
In Section 4.3, phonon-induced tunnel transitions in $F-V_{K}$ and $F^{\prime}-V_{K}$ pairs have been already considered, and it is just these processes that are responsible for TSL at 11-15 K in LiF. A concept of phonon-induced tunnel transitions was earlier used for the interpretation of the thermal quenching of STE emission at $T \geq 12 \mathrm{~K}$ in $\mathrm{KCl}$ preliminary irradiated at $4.2 \mathrm{~K}$ [41]. This concept can be applied to pure LiF crystals irradiated at 4-6 K as well. Lattice vibration spectra as well as the dependencies of the density of vibration states on vibration frequency were studied for $\mathrm{LiF}$ crystals $[50,51]$. In $\mathrm{LiF}$, the frequencies of transverse and longitudinal optical vibrations cover the region of $v=300-638 \mathrm{~cm}^{-1}$, while the acoustic vibrations are characterized by $v=0-350 \mathrm{~cm}^{-1}$. The vibration spectra of LiF can be compared with those of $\mathrm{MgO}, \mathrm{TiO}_{2}$ [51] and $\mathrm{LiH}, \mathrm{LiD}$ crystals [52]. According to the analysis of these vibration spectra, the vibrations connected with the presence of hydrogen, deuterium, magnesium and titanium impurities in LiF crystals appear as local vibrations, i.e. their frequencies exceed the limiting value of lattice vibrations $\left(v_{1}=638 \mathrm{~cm}^{-1}\right)$. Contrary to $\mathrm{LiH}$ [52], there is no energy gap between the acoustic and optical vibration branches in LiF. In $\mathrm{LiF}$, the vibration frequency in $\mathrm{V}_{\mathrm{K}}$ centres $\left(\mathrm{F}_{2}^{-}\right.$quasi-molecules) is predicted at $\sim 450 \mathrm{~cm}^{-1}$ and approximately the same value is suggested for $\mathrm{H}$ centres [53]. It was mentioned already that the activation energy of the direct tunnel radiative transitions $(5.5 \mathrm{eV}$ emission) with the participation of $\mathrm{F}^{\prime}$ and $\mathrm{V}_{\mathrm{K}}$ centres is about $10 \mathrm{meV}\left(80 \mathrm{~cm}^{-1}\right)$. These tunnel transitions are induced by acoustic lattice vibrations. A further study of phonon-induced tunnel TSL in the region of 9-16 K, connected with the processes within GSCDs, lies ahead.

\section{Concluding remarks}

A complex investigation of several nominally-pure as well as doped with $\mathrm{Mg}, \mathrm{Ti}$ or $\mathrm{Na} \mathrm{LiF}$ single crystals has been performed in the present study at low temperatures $(6-200 \mathrm{~K})$ after the sample irradiation by an electron beam, X-rays and VUV photons of several energies. The analysis of the excitation spectra of various emissions measured for the first time in $\mathrm{LiF}$ crystals at $9 \mathrm{~K}$ using VUV radiation of $10-33 \mathrm{eV}$ allowed to confirm that an emission band at $3.4 \mathrm{eV}$ is caused by the radiative decay of intrinsic STEs. Contrary to 4.6 and $5.8 \mathrm{eV}$ extrinsic emissions, the efficiency of the $3.4 \mathrm{eV}$ emission is especially high in the region of exciton absorption (12.4-14.2 eV), and this emission is also excited by $28-33 \mathrm{eV}$ photons, which form hot conduction electrons able to create secondary anion excitons.

It is demonstrated that the TSL at $100-170 \mathrm{~K}$ is different after the irradiation of LiF by $13.8 \mathrm{eV}$ or $17 \mathrm{eV}$ photons, which selectively form excitons or e-h pairs, respectively. The 
irradiation of a sample by X-rays or an electron beam leads to the appearance of the TSL more similar to that in the case of the $17 \mathrm{eV}$-photon irradiation, thus confirming the earlier conclusion that the number of e-h pairs formed at X-irradiation of other alkali halides (e.g., KI $[8,54])$ is several times as high as the number of anion excitons. The creation of several defects has been detected in irradiated LiF crystals. The TSL peaks at $13 \mathrm{~K}, 23,28,40,60$, $115,130,145$ and $160 \mathrm{~K}$ have been detected at the subsequent heating of LiF previously irradiated at 6-9 K. The TSL curves were measured for a certain intrinsic $(3.4 \mathrm{eV})$ or extrinsic (4.6 or $5.5 \mathrm{eV}$ ) emission. The analysis of the obtained results (as well as the ENDOR data on $\mathrm{H}$ centres [15]) allowed to conclude that a hopping diffusion of interstitial fluorine ions (I centres) and $\mathrm{H}$ centres takes place at 20-30 and 50-65 K, respectively. Two-electron $\mathrm{F}^{\prime}$ centres have been experimentally revealed in LiF and their thermal ionisation occurs at 160-170 K.

The peak at $\sim 13 \mathrm{~K}$ (recently revealed by our group in X-irradiated LiF [19]), the most intense after electron or X-irradiation, was not detected after a LiF irradiation by 13.8 or 17 $\mathrm{eV}$ photons at $8 \mathrm{~K}$. The creation of a spatially correlated anion exciton and e-h pair under conditions of EE multiplication causes the appearance of the TSL at 12-13 K: an exciton decays into an F-H pair, a hole forms a $\mathrm{V}_{\mathrm{K}}$ in a spatially close region and an electron transforms $\mathrm{H}$ into I interstitial (as a result, we have an F-I- $\mathrm{V}_{\mathrm{K}}$ group) or an F centre into $\mathrm{F}^{\prime}$ (an $\mathrm{F}^{\prime}-\mathrm{H}-\mathrm{V}_{\mathrm{K}}$ group). The analysis of the spectra of the TSL at $12-14 \mathrm{~K}$ and of the influence of an additional F- or $\mathrm{F}^{\prime}$-illumination of irradiated samples on this TSL showed that phononinduced radiative tunnel recombination of $\mathrm{F}^{\prime}-\mathrm{V}_{\mathrm{K}}(5.6 \mathrm{eV}), \mathrm{F}-\mathrm{V}_{\mathrm{K}}(3.4 \mathrm{eV})$ or $\mathrm{F}-\mathrm{H}(\sim 3 \mathrm{eV})$ occur within the groups of spatially correlated defects at the heating of the sample.

\section{Acknowledgements}

We are grateful to Drs. M. Kirm, A. Kotlov and V. Nagirnyi for assistance in synchrotron measurements. This work was supported by the European Community - Research Infrastructure Action under the FP6 "Structuring the European Research Area" Programme (through the Integrated Infrastructure Initiative "Integrating Activity on Synchrotron and Free Electron Laser Science"). 


\section{References}

1. Benedict L X, Shirley E L and Bohn R B 1998 Phys. Rev. Lett. 804514

2. Wang N-P, Rohlfing M, Krüger P, Pollmann J 2003 Phys. Rev. B 67115111

3. Rao K K, Moravec T J, Rife J C and Dexter R N 1975 Phys. Rev. B 125937

4. Nepomnyachikh A I, Radzhabov E A and Erganov A V 1984 Colour Centres and Luminescence of LiF Crystals (Novosibirsk: Nauka)

5. McKeever S W S, Moscovitch M and Townsend P D 1995 Thermoluminescence Dosimetry Materials: Properties and Uses (Ashford: Nuclear Technology Publishing)

6. Haensel R, Kunz C and Sonntag B 1968 Phys. Rev. Lett. 20262

7. Zimmerer G 1991 Nucl. Instr. and Meth. A 308178

8. Lushchik Ch and Lushchik A 1989 Decay of Electronic Excitations with Defect Formation in Solids. (Moscow: Nauka)

9. Tanimura K and Itoh N 1984 J. Phys. Chem. Solids 45323

10. Song K S and Williams R T 1996 Self-Trapped Excitons, Second Edition (Berlin: Springer)

11. Känzig W 1960 J. Phys. Chem. Solids 17 80; 88

12. Schoemaker D 1973 Phys. Rev. B 7786

13. Känzig W and Woodruff T O 1958 J. Phys. Chem. Solids 970

14. Lushchik A, Vasil'chenko E, Galaganov V, Kolk J, Seeman V and Frorip A 1990 Izv. Akad. Nauk Latv.SSR, Ser. Fiz. Tekh. 333

15. Chu Y H and Mieher R L 1968 Phys. Rev. Lett. 201289

16. Dakss M L and Mieher R L 1969 Phys. Rev. 1871053

17. Lushchik Ch B 1982 Excitons ed Rashba E I and Sturge M D (Amsterdam: NorthHolland) pp 506-541

18. Roessler D M and Walker W C 1967 J. Phys. Chem. Solids 281507

19. Vasil'chenko E, Kudryavtseva I, Lushchik A, Lushchik Ch and Nagirnyi V 2005 Phys. Status Solidi c 2405

20. Watanabe M, Nishida H and Ejiri A 1974 Vacuum Ultraviolet Radiation Physics ed Koch E-E, Haensel R and Kunz C (Braunschweig: Vieweg) pp 370-374

21. Pooley D and Runciman W A 1970 J. Phys. C: Solid St. Phys. 31815

22. Wasiela A and Block D 1976 J. Physique Colloq. 37 C7-221

23. Block D and Wasiela A 1979 Solid State Commun. 28445.

24. Lisitsyna L A, Grechkina T V, Korepanov V I and Lisitsyn V M 2001 Phys. Solid State 431680 
25. Lushchik A, Feldbach E, Kink R, Lushchik Ch, Kirm M and Martinson I 1996 Phys. Rev. B 535379

26. Pustovarov V A, Shul'gin B V, Kirm M, Kidibaev M M and Zhamangulov AA 2000 Opt. Spectrosc. 88713

27. Kirm M, Lushchik A and Lushchik Ch 2005 Phys. Status Solidi a 202213

28. Aboltin D E, Grabovskis V J, Kangro A R, Lushchik Ch B, O'Konnel-Bronin A A, Vitol I K and Zirap V E 1978 Phys. Status Solidi a 47667

29. Grabovskis V J and Vitols I K 1979 J. Lumin. 20337

30. Shvarts K K, Vitol A Ya, Kalninsh D O, Lusis D Yu and Podin'sh A 1967 Bull. Acad. Sci. USSR Ser. Phys. (USA) 312071

31. Solid State Dosimetry 2002 ed Horowitz Y S and Oster L (Nuclear Technology Publishing) (Proc. 13 ${ }^{\text {th }}$ Intern. Conf. Solid State Dosimetry, Athens, Greece, 2001)

32. Pung L 1966 Trudy Inst. Fiz. Akad Nauk Est. SSR 34164

33. Townsend P D, Clark C D and Levy P W 1967 Phys. Rev. 155908

34. Mayhugh M R 1970 J. Appl. Phys. 414776

35. Cooke D W and Rhodes J F 1981 J. Appl. Phys. 524244

36. Lynch D W and Robinson D A 1968 Phys. Rev. 1741050

37. La S Y and Bartram R H 1966 Phys. Rev. 144670

38. Lushchik A Ch and Frorip A G 1990 Phys. Status Solidi b 161525

39. Kolk Yu V and Lushchik A Ch 1986 Sov. Phys. Solid State 28805

40. Lushchik Ch, Kolk J, Lushchik A and Lushchik N 1984 Phys. Status Solidi a 86219

41. Lushchik A Ch and Lushchik Ch B 1992 Bull. Russ. Acad. Sci. Phys. (USA) 56201

42. Kirm M, Lushchik A, Lushchik Ch, Martinson I, Nagirnyi V and Vasil'chenko E 1998 J. Phys.: Condens. Matter 103509

43. Kondo Y, Hirai M and Ueta M 1972 J. Phys. Soc. Japan 33151

44. Lushchik A. Kirm M, Lushchik Ch and Vasil'chenko E 2000 Nucl. Instr. and Meth. B 166-167529

45. Williams R T 1989 Opt. Eng. 281024

46. Maiste A A, Saar A M-E and Elango M A 1973 JETP Lett. 1897

47. Arakawa E T and Williams M W 1976 Phys. Rev. Lett. 36333

48. Feldbach E, Kirm M, Lushchik A, Lushchik Ch and Martinson I 2000 J. Phys.: Condens. Matter 121991

49. Kamada M, Takahashi N and Hirose S 1999 J. Electron Spectrosc. Relat. Phenom. 101103599 
50. Dolling G, Smith H G, Nicklow R M, Vijayarghavan P R and Wilkinson M K 1968 Phys. Rev. 168970

51. Bilz H and Kress E 1979 Phonon Dispersion Relations in Insulators (Berlin: Springer)

52. Lushchik Ch B, Gavrilov F F, Zavt G S, Plekhanov V G and Cholakh S O 1985 Electronic Excitations and Defects In Lithium Hydride (Moscow: Nauka, 1989)

53. Harding J H 1980 J. Phys. C: Solid State Phys. 133505

54. Vasil'chenko E A, Lushchik Ch B and Osmonaliev K 1986 Sov. Phys. Solid State 28 1113 


\section{Captions}

Figure 1. (a) Reflection spectrum (dashed line) and the excitation spectra of $3.4 \mathrm{eV}$ (solid line) and $4.6 \mathrm{eV}$ emissions (oo) measured for a LiF-1 crystal at $9 \mathrm{~K}$.

(b) Emission spectra of LiF-1 excited by synchrotron radiation of $12.9 \mathrm{eV}$ (solid curves) at 9 $\mathrm{K}$. The spectra were measured for a time-integrated (TI), fast $\left(\mathrm{TW}_{\mathrm{f}}, \Delta t=26 \mathrm{~ns}, \delta t=8 \mathrm{~ns}\right)$ and slow component $\left(\mathrm{TW}_{\mathrm{s}}, \Delta t=148 \mathrm{~ns}, \delta t=52 \mathrm{~ns}\right)$. The spectrum of the time-integrated emission under $16.2 \mathrm{eV}$-photon excitation of LiF-1 at $9 \mathrm{~K}$ (dashed curve).

Figure 2. Cathodoluminescence (solid line), tunnel luminescence (phosphorescence) spectra $(\Delta \Delta)$ and the spectra of TSL at 11-14 K (oo) measured for LiF-1 (a) and LiF-3 crystals (b). Cathodoluminescence and phosphorescence spectra are measured at $6 \mathrm{~K}$. The crystals were irradiated by $30 \mathrm{keV}$ electrons at $6 \mathrm{~K}, \beta=10 \mathrm{~K} \mathrm{~min}^{-1}$ at TSL measurements.

Figure 3. The excitation spectra for a time-integrated (TI), fast $\left(\mathrm{TW}_{\mathrm{f}}, \Delta t=26 \mathrm{~ns}, \delta t=8 \mathrm{~ns}\right)$ and slow $\left(\mathrm{TW}_{\mathrm{s}}, \Delta t=148 \mathrm{~ns}, \delta t=52 \mathrm{~ns}\right.$ ) component of $5.9 \mathrm{eV}$ (solid lines) or $4.23 \mathrm{eV}$ (dashed lines) emissions and the reflection spectrum $(\bullet \bullet)$ in a LiF-1 crystal at $9 \mathrm{~K}$. The excitation spectra of time-integrated $3.4 \mathrm{eV}$ emission in LiF-1 (oo) and LiF-2 $(\Delta \Delta)$ crystals at $9 \mathrm{~K}$.

Figure 4. TSL curves measured for $3.5 \mathrm{eV}$ emission in LiF-1 (solid line) and LiF-3 (dotted line) crystals irradiated by an electron beam $\left(30 \mathrm{keV}, 10 \mathrm{nA} \mathrm{mm} \mathrm{mm}^{-2}\right)$ at $6 \mathrm{~K} . \beta=10 \mathrm{~K} \mathrm{~min}^{-1}$.

Figure 5. Thermoactivation characteristics of LiF-1 (a) and LiF-3 crystals (b), heating rate of $\beta=5 \mathrm{~K} \mathrm{~min}^{-1}$. Time-integrated TSL measured for the sample irradiated by $13.8 \mathrm{eV}$ (dashed curve) and $17 \mathrm{eV}$ (solid curves) photons at $8 \mathrm{~K}$. The annealing of the optical absorption at 3.6 $\mathrm{eV}(\bullet \bullet)$ and EPR signal of $\mathrm{V}_{\mathrm{K}}$ centres (oo) in a crystal X-irradiated $(50 \mathrm{kV}, 15 \mathrm{~mA})$ at $80 \mathrm{~K}$ or $77 \mathrm{~K}$, respectively. Time-integrated TSL (dotted lines) measured for the sample X-irradiated at $295 \mathrm{~K}$ and additionally illuminated by $4.88 \mathrm{eV}$ photons at $80 \mathrm{~K}$.

Figure 6. (a) TSL curves measured for 3.3 and $4.8 \mathrm{eV}$ emissions in LiF-1 X-irradiated at $6 \mathrm{~K}$. TSL curves are measured for $3.3 \mathrm{eV}$ emission after 5 or $60 \mathrm{~min}$ (solid lines) and for $4.8 \mathrm{eV}$ emission after $30 \mathrm{~min}$ irradiation (dashed line), $\beta=5 \mathrm{~K} \mathrm{~min}^{-1}$. Temperature dependence of the intensity of a steady STE emission $(3.4 \mathrm{eV})$ at the excitation by X-rays (dotted line).

Figure 7. TSL curves measured for $5.4 \mathrm{eV}$ (a) or $3.4 \mathrm{eV}$ (b-d) emission in LiF-1 (a, b, d) and LiF-3 (c) crystals irradiated by $30 \mathrm{keV}$ electrons at $6 \mathrm{~K}, \beta=10 \mathrm{~K} \mathrm{~min}^{-1}$.

a, b, c - Experimental curve (dotted lines), components of the TSL decomposition described by the first order kinetics (thin solid lines) and their sum (thick solid lines). 
d - Experimental curve and elementary decomposition components after the electron irradiation of a sample (solid lines, thick one - experimental curve) and after an additional $\mathrm{F}^{\prime}$ illumination at $6 \mathrm{~K}$ (dashed lines, thick one - experimental curve). 

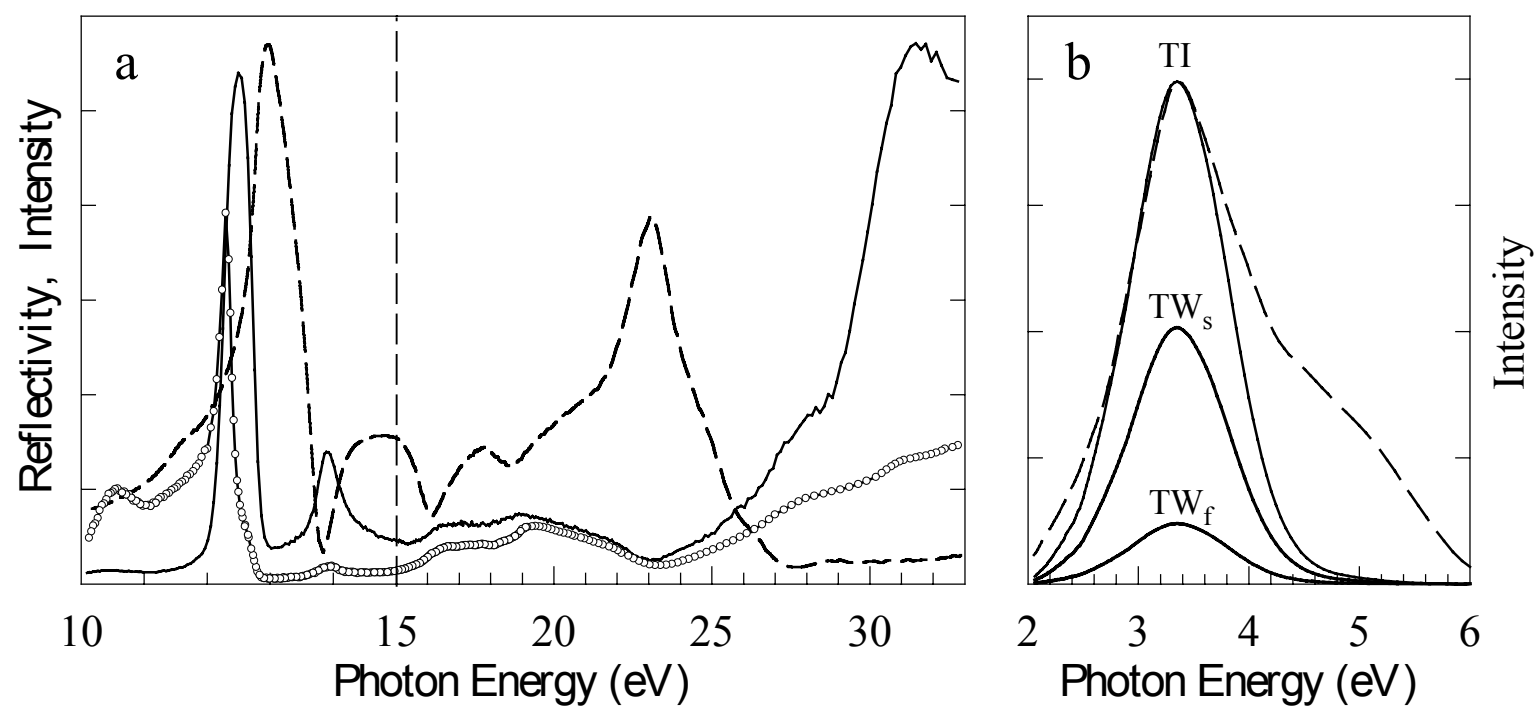

Figure 1. (a) Reflection spectrum (dashed line) and the excitation spectra of $3.4 \mathrm{eV}$ (solid line) and 4.6 eV emissions (oo) measured for a LiF-1 crystal at $9 \mathrm{~K}$.

(b) Emission spectra of LiF-1 excited by synchrotron radiation of $12.9 \mathrm{eV}$ (solid curves) at 9 $\mathrm{K}$. The spectra were measured for a time-integrated (TI), fast $\left(\mathrm{TW}_{\mathrm{f}}, \Delta t=26 \mathrm{~ns}, \delta t=8 \mathrm{~ns}\right)$ and slow component $\left(\mathrm{TW}_{\mathrm{s}}, \Delta t=148 \mathrm{~ns}, \delta t=52 \mathrm{~ns}\right)$. The spectrum of time-integrated emission under $16.2 \mathrm{eV}$-photon excitation of LiF-1 at $9 \mathrm{~K}$ (dashed curve). 

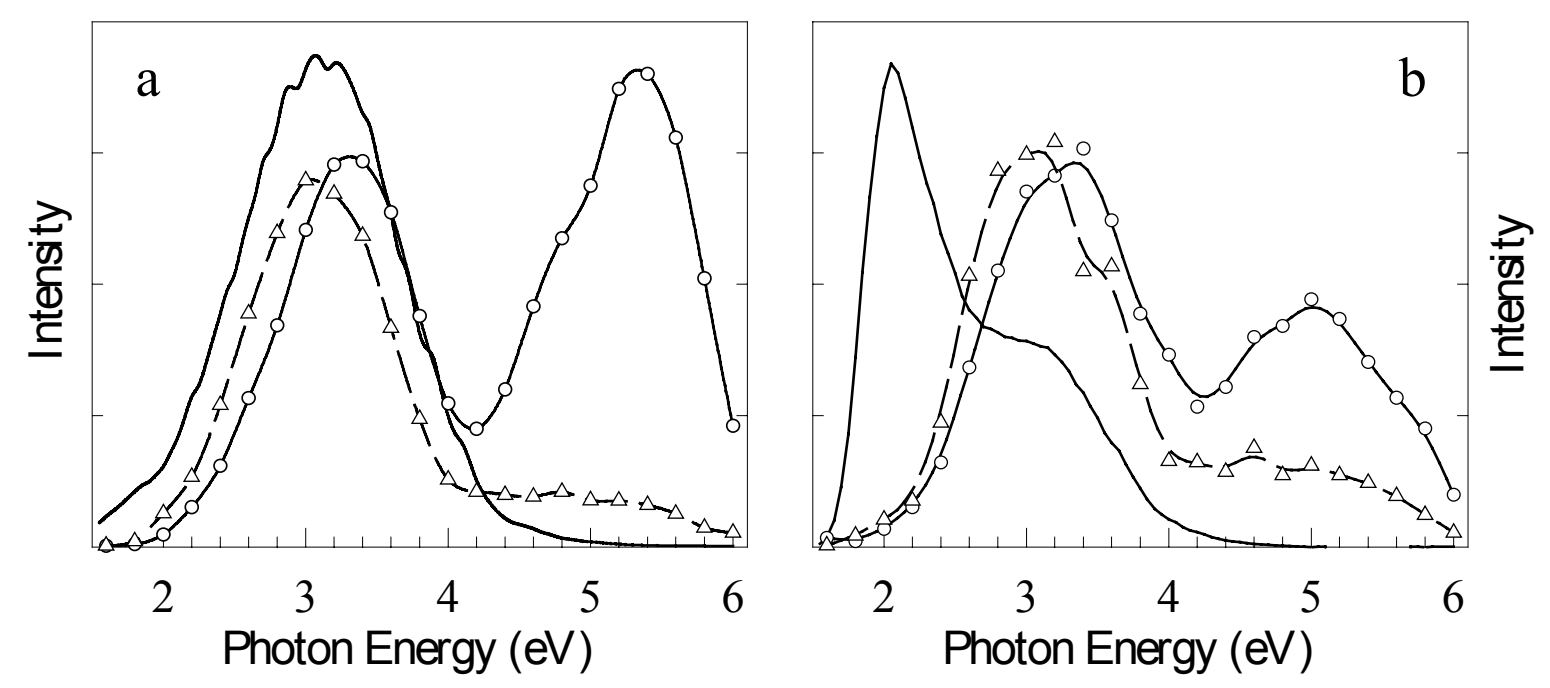

Figure 2. Cathodoluminescence (solid line), tunnel luminescence (phosphorescence) spectra $(\Delta \Delta)$ and the spectra of TSL at 11-14 K (oo) measured for LiF-1 (a) and LiF-3 crystals (b). Cathodoluminescence and phosphorescence spectra are measured at $6 \mathrm{~K}$. The crystals were irradiated by $30 \mathrm{keV}$ electrons at $6 \mathrm{~K}, \beta=10 \mathrm{~K} \mathrm{~min}^{-1}$ at TSL measurements. 


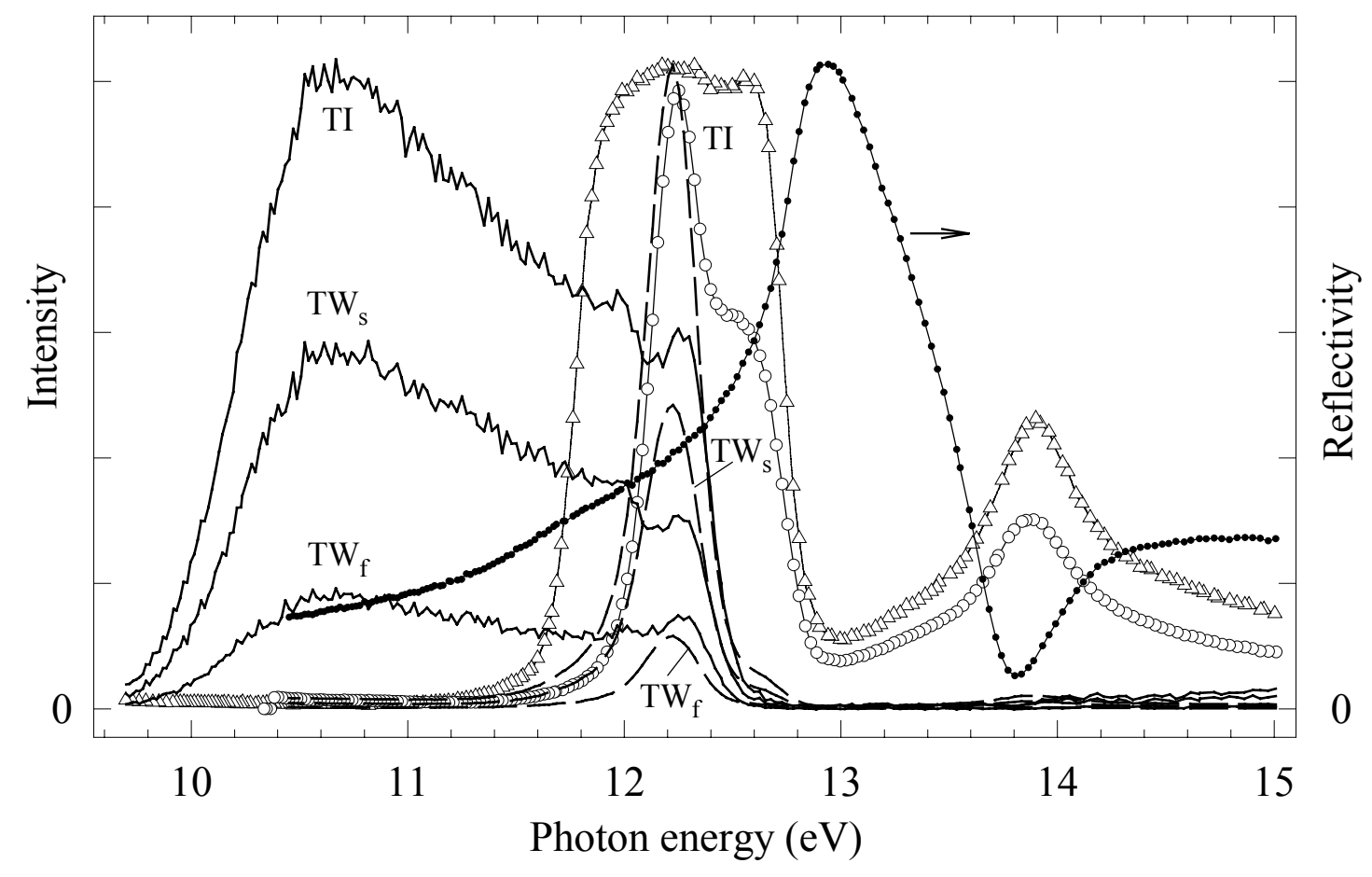

Figure 3. The excitation spectra for a time-integrated (TI), fast ( $\left.\mathrm{TW}_{\mathrm{f}}, \Delta t=26 \mathrm{~ns}, \delta t=8 \mathrm{~ns}\right)$ and slow $\left(\mathrm{TW}_{\mathrm{s}}, \Delta t=148 \mathrm{~ns}, \delta t=52 \mathrm{~ns}\right.$ ) component of $5.9 \mathrm{eV}$ (solid lines) or $4.23 \mathrm{eV}$ (dashed lines) emissions and the reflection spectrum $(\bullet \bullet)$ in a LiF-1 crystal at $9 \mathrm{~K}$. The excitation spectra of time-integrated $3.4 \mathrm{eV}$ emission in LiF-1 (oo) and LiF-2 $(\Delta \Delta)$ crystals at $9 \mathrm{~K}$. 


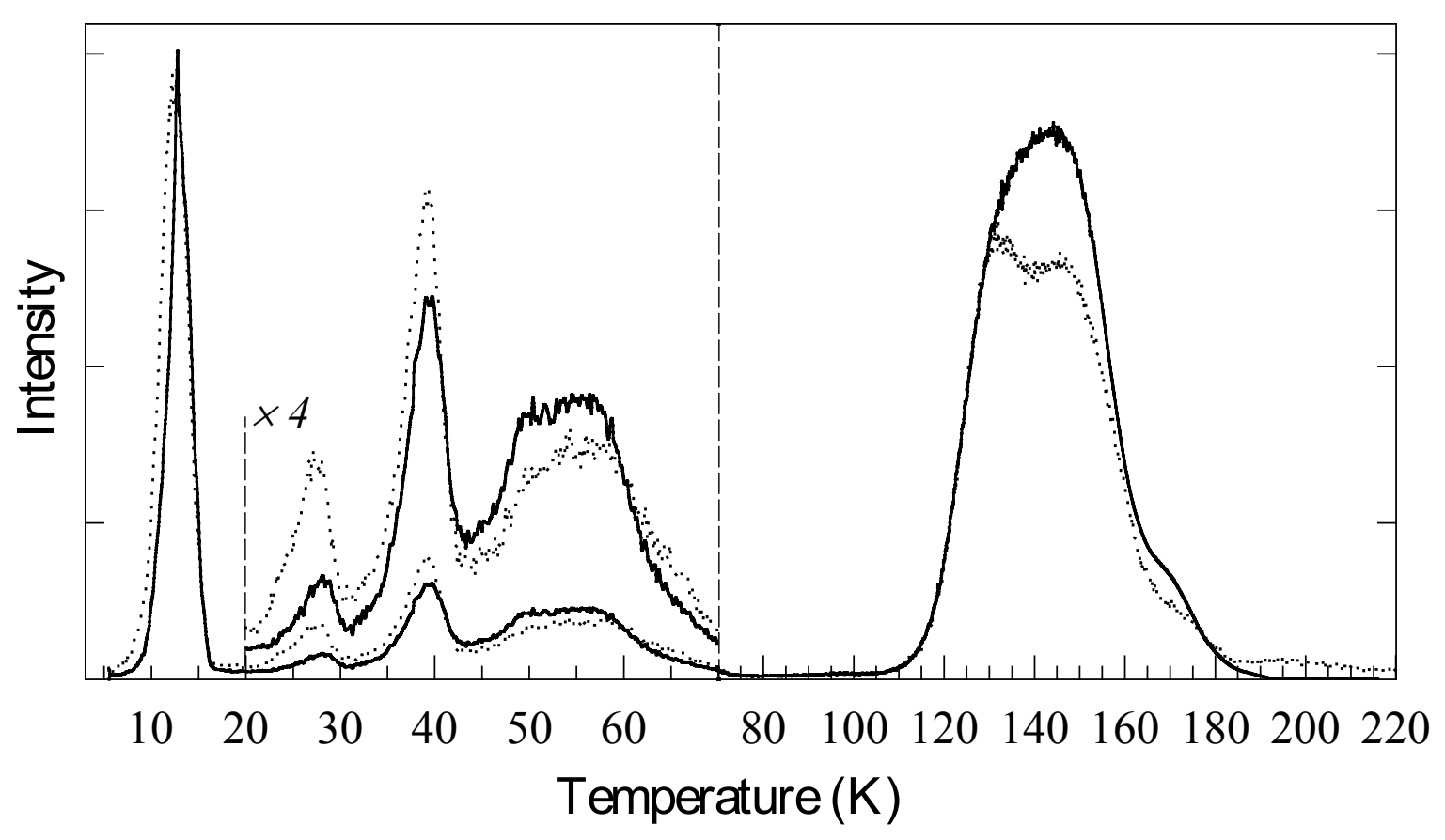

Figure 4. TSL curves measured for $3.5 \mathrm{eV}$ emission in LiF-1 (solid line) and LiF-3 (dotted line) crystals irradiated by an electron beam $\left(30 \mathrm{keV}, 10 \mathrm{nA} \mathrm{mm}{ }^{-2}\right)$ at $6 \mathrm{~K} . \beta=10 \mathrm{~K} \mathrm{~min}^{-1}$. 

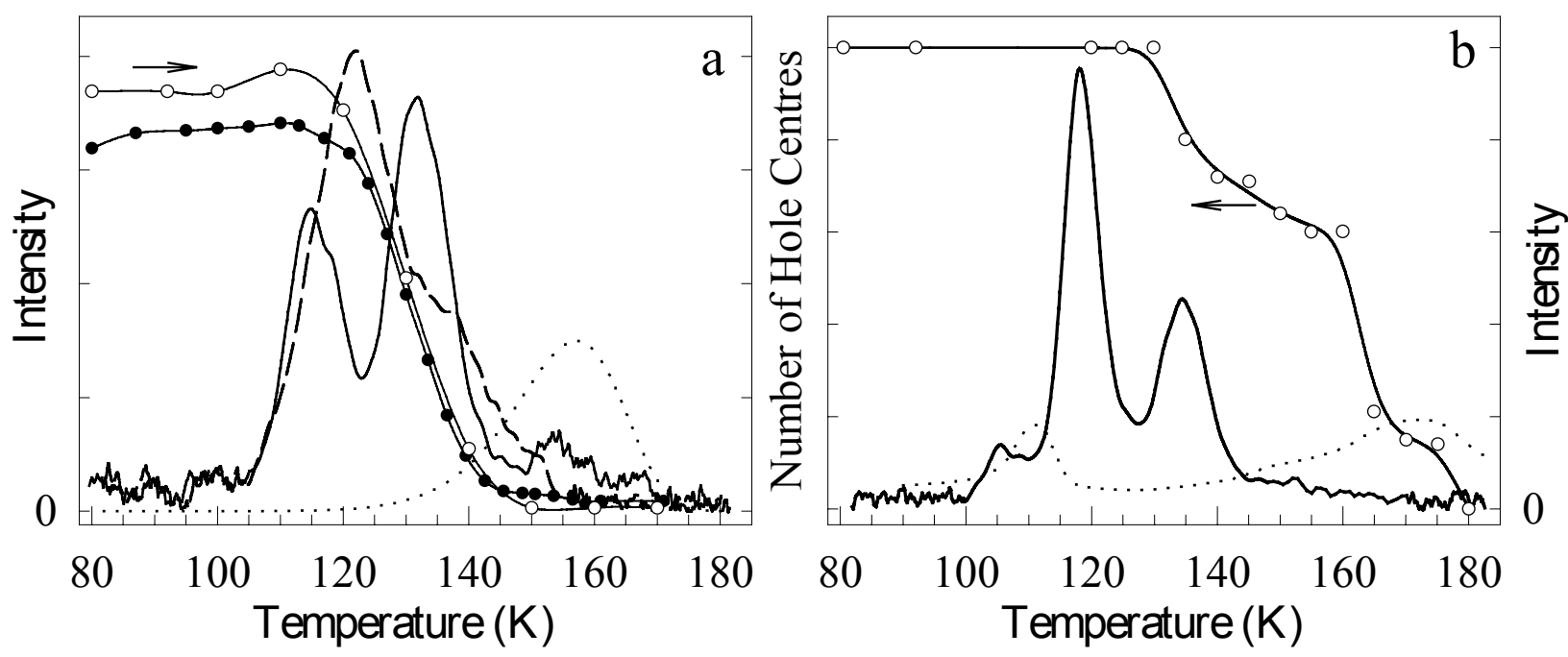

Figure 5. Thermoactivation characteristics of LiF-1 (a) and LiF-3 crystals (b), heating rate of $\beta=5 \mathrm{~K} \mathrm{~min}^{-1}$. Time-integrated TSL measured for the sample irradiated by $13.8 \mathrm{eV}$ (dashed curve) and $17 \mathrm{eV}$ (solid curves) photons at $8 \mathrm{~K}$. The annealing of the optical absorption at 3.6 $\mathrm{eV}(\bullet \bullet)$ and EPR signal of $\mathrm{V}_{\mathrm{K}}$ centres (oo) in a crystal $\mathrm{X}$-irradiated $(50 \mathrm{kV}, 15 \mathrm{~mA})$ at $80 \mathrm{~K}$ or $77 \mathrm{~K}$, respectively. Time-integrated TSL (dotted lines) measured for the sample X-irradiated at $295 \mathrm{~K}$ and additionally illuminated by $4.88 \mathrm{eV}$ photons at $80 \mathrm{~K}$. 


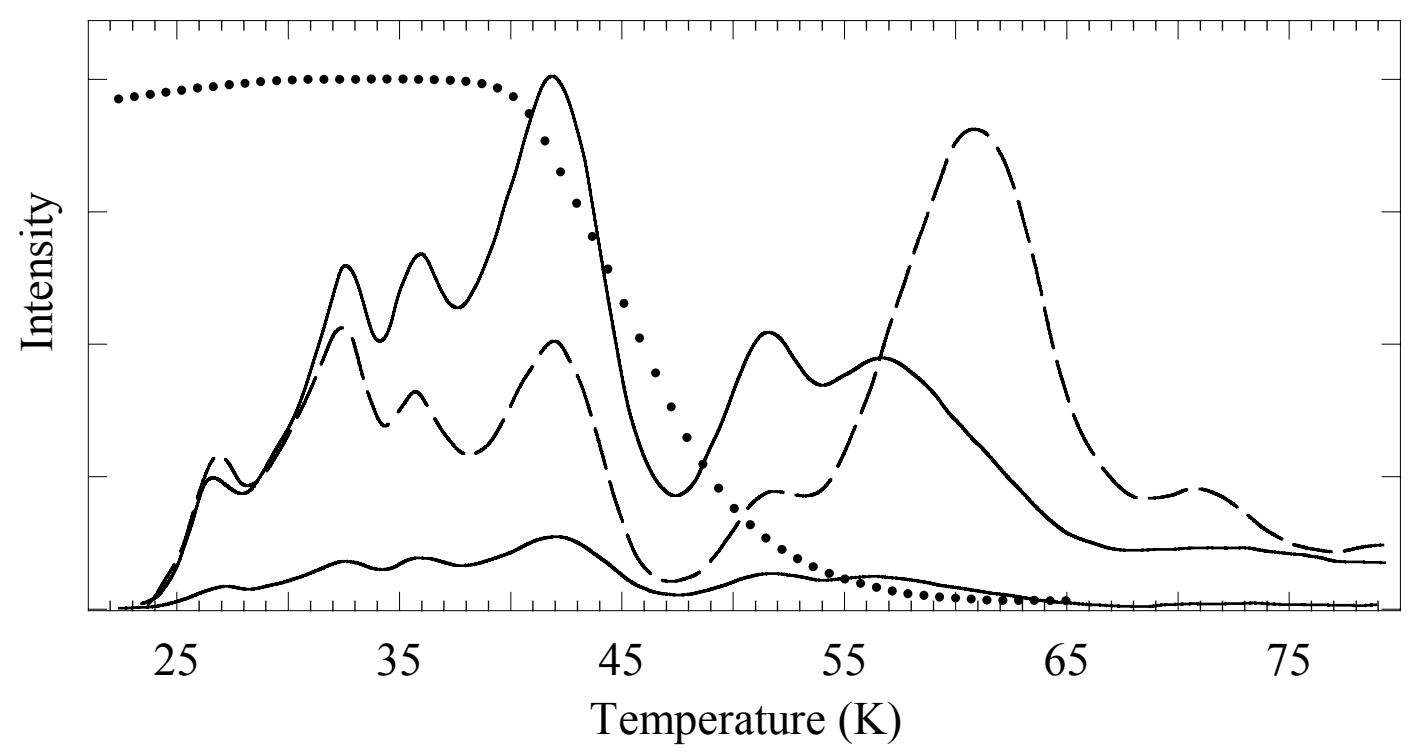

Figure 6. (a) TSL curves measured for 3.3 and $4.8 \mathrm{eV}$ emissions in LiF-1 X-irradiated at $6 \mathrm{~K}$. TSL curves are measured for $3.3 \mathrm{eV}$ emission after 5 or $60 \mathrm{~min}$ (solid lines) and for $4.8 \mathrm{eV}$ emission after $30 \mathrm{~min}$ irradiation (dashed line), $\beta=5 \mathrm{~K} \mathrm{~min}^{-1}$. Temperature dependence of the intensity of a steady STE emission $(3.4 \mathrm{eV})$ at the excitation by X-rays (dotted line). 


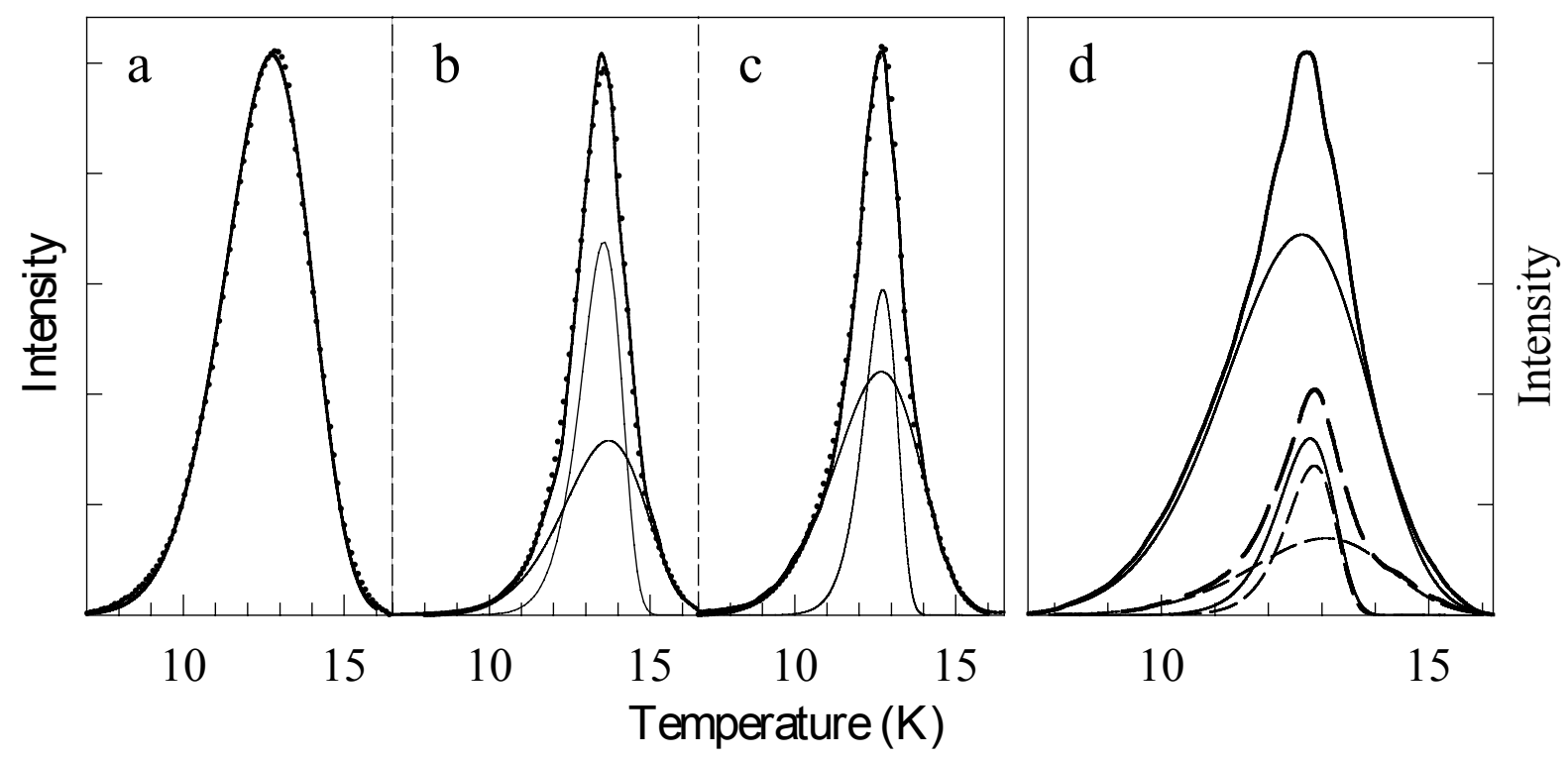

Figure 7. TSL curves measured for $5.4 \mathrm{eV}$ (a) or $3.4 \mathrm{eV}$ (b-d) emission in LiF-1 (a, b, d) and LiF-3 (c) crystals irradiated by $30 \mathrm{keV}$ electrons at $6 \mathrm{~K}, \beta=10 \mathrm{~K} \mathrm{~min}^{-1}$.

a, b, c - Experimental curve (dotted lines), components of the TSL decomposition described by the first order kinetics (thin solid lines) and their sum (thick solid lines). d Experimental curve and elementary decomposition components after the electron irradiation of a sample (solid lines, thick one - experimental curve) and after an additional $\mathrm{F}^{\prime}$ illumination at $6 \mathrm{~K}$ (dashed lines, thick one - experimental curve). 